University of South Florida

DIGITAL COMMONS

Digital Commons @ University of

@ UNIVERSITY OF SOUTH FLORIDA

South Florida

Marine Science Faculty Publications

College of Marine Science

$11-1-1988$

\title{
Instability Waves in the Equatorial Atlantic Ocean
}

Robert H. Weisberg

University of South Florida, weisberg@marine.usf.edu

T. J. Weingartner

University of South Florida

Follow this and additional works at: https://digitalcommons.usf.edu/msc_facpub

Part of the Marine Biology Commons

\section{Scholar Commons Citation}

Weisberg, Robert H. and Weingartner, T. J., "Instability Waves in the Equatorial Atlantic Ocean" (1988). Marine Science Faculty Publications. 141.

https://digitalcommons.usf.edu/msc_facpub/141

This Article is brought to you for free and open access by the College of Marine Science at Digital Commons @ University of South Florida. It has been accepted for inclusion in Marine Science Faculty Publications by an authorized administrator of Digital Commons @ University of South Florida. For more information, please contact digitalcommons@usf.edu. 


\title{
Instability Waves in the Equatorial Atlantic Ocean
}

\author{
ROBERT H. WEISBERG AND THOMAS J. WEINGARTNER \\ Department of Marine Science, University of South Florida, St. Petersburg, Florida
}

(Manuscript received 28 December 1987, in final form 17 May 1988)

\section{ABSTRACT}

\begin{abstract}
Evidence is presented for the generation of planetary waves by barotropic instability within the cyclonic shear region of the Atlantic Ocean's South Equatorial Current (SEC). Immediately following the springtime intensification of the southeast trade wind, which accelerates the SEC westward, a packet of waves with central periodicity of around 25 days is observed lasting for about three cycles. Independent wavenumber analyses on 1983 and 1984 data give nearly identical zonal wavelengths and phase speed estimates of around $1100 \mathrm{~km}$ and $-50 \mathrm{~cm} \mathrm{~s}^{-1}$. The waves are anisotropic and spatially inhomogeneous with generation confined primarily to the mixed layer.

An energetics analysis using 1983 data centered upon the equator at $28^{\circ} \mathrm{W}$ shows a rapid increase in total perturbation energy (TPE) reaching values of $2000 \mathrm{erg} \mathrm{cm}^{-3}$ within two weeks. The subsequent decrease in TPE at this location is due primarily to meridional pressure-work divergence. Baroclinic instability is negligible because both the meridional and zonal components are small and cancelling.

Thermodynamically, the waves effect a southward heat transport during the period when the North Equatorial Countercurrent (NECC) is most rapidly gaining heat, suggesting that the waves act to regulate the heat stored in the NECC. Also the Reynolds' heat flux convergence upon the equator appears to halt the upwelling induced cooling and to increase sea surface temperature. In 1983 this convergence was equal to the climatological atmosphere-ocean net heat flux.

Dynamically, the waves decelerate the SEC north of the equator and reduce its shear. This occurs simultaneously with a deceleration of the SEC by the basinwide adjustment of the zonal pressure gradient (ZPG). The seasonal modulation of the waves is therefore a consequence of both the ZPG response to seasonally varying wind stress as well as the instability itself since both are stabilizing. The basin size and hence the ZPG adjustment time differences between the Atlantic and Pacific Oceans would thus account for the observed differences in wave season durations between these two oceans.
\end{abstract}

\section{Introduction}

Wavelike oscillations of the zonal currents on the equator of the Atlantic Ocean were first noted by Duing et al. (1975) during the GATE program. Additional measurements since then have shown these to be common features of both the Atlantic and Pacific equatorial currents systems. Weisberg (1987) provides a synopsis of their theoretical and observational history. While the observational base is not extensive, certain features of the waves are fairly well defined. In both oceans the waves are zonally inhomogeneous. They occupy limited portions of the central ocean basins where they are confined principally to the mixed layer between $2^{\circ} \mathrm{S}$ and $4^{\circ} \mathrm{N}$. Their appearance is seasonally modulated and they have time and zonal length scales of about three weeks and $1000 \mathrm{~km}$.

Philander $(1976,1978)$ demonstrated analytically that barotropic instability within the South Equatorial Current (SEC) is capable of radiating waves of the ob-

Corresponding author address: Dr. Robert $\mathrm{H}$. Weisberg, Dept. of Marine Science, University of South Florida, 1407 th Avenue South, St. Petersburg, FL 33701. served wavelength and period with an $e$-folding scale of about two weeks. Cox's (1980) multilevel numerical model results corroborated Philander's findings and indicated that baroclinic instability, while of lesser importance, is also a source of perturbation energy. In the Pacific Ocean, Hansen and Paul (1984, hereafter referred to as HP) estimated turbulent energy production by barotropic and baroclinic instability processes and found both to be of equal importance. In the Atlantic Ocean, Weisberg (1984) found that the seasonal appearance of the waves coincided with that of the offdiagonal horizontal Reynolds' stress. Moreover the associated deformation work was of the correct sign and magnitude to account for the observed wave energy level, suggesting that barotropic instability was the principal mechanism of wave generation.

Less is known of the waves' role in the heat and momentum balances of the upper ocean and gaps prevail in the understanding of their energetics. Philander et al. (1986, hereafter referred to as PHP) and HP estimate that the meridional convergence of Reynolds heat flux is equivalent to atmospheric heating and opposes the poleward transport of heat by Ekman divergence. Bryden et al. (1987) and HP estimate that the 
equatorial convergence of westward momentum by the perturbations is approximately the same as that imparted by the wind stress. Cox (1980) showed that the instabilities radiated energy into the deep ocean as baroclinic Rossby-gravity and Rossby waves. Deep expressions of these waves have been reported by Harvey and Patzert (1976) in the Pacific and by Weisberg et al. (1979) in the Atlantic. Ray tracing arguments by Weisberg and Horigan (1981) suggested wave origination near the surface of the central Atlantic in June and July, consistent in location and timing with generation by instability within the SEC.

Current meter data from surface moorings deployed during the SEQUAL (Seasonal Response of the Equatorial Atlantic) and FOCAL (Francais Ocean et Climat dans l'Atlantique Equatorial) programs are used herein to further evaluate the waves' properties and their influence upon upper ocean processes. The plan of the paper is as follows. Section 2 describes the data and the wave kinematics. Perturbation energy, heat, and momentum flux time series are presented in section 3. These time series illustrate the spatial domain and seasonal modulation of the waves and provide a basis for understanding their energetics and their interactions with the background temperature and velocity fields. Section 4 considers the local perturbation energy balance centered on the equator at $28^{\circ} \mathrm{W}$ during 1983 . The waves' influences upon the momentum and heat balances are then developed in section 5 and the results are discussed relative to numerical models and previous observations. Section 6 provides a summary.

\section{Kinematical description}

The current meter array consists of two parts: a meridional array along $28^{\circ} \mathrm{W}$ with moorings at $0.75^{\circ} \mathrm{S}$, $0.0^{\circ}, 0.75^{\circ}, 1.75^{\circ}, 3.0^{\circ}$ and $6.0^{\circ} \mathrm{N}$ and a zonal array along the equator with moorings at $28^{\circ}, 24^{\circ}, 15^{\circ}$ and $4^{\circ} \mathrm{W}$. Figure 1 shows a plan view of this array in relation to the meridional distribution of surface zonal currents, and the current meter depths in relation to the background temperature structure. The surface currents, derived using ship drift reports between $25^{\circ}$ and $30^{\circ} \mathrm{W}$ by Richardson and Mckee (1984), are for a climatologically averaged June. They consist of the eastward flowing North Equatorial Countercurrent (NECC) bounded by the westward flows of the SEC and the North Equatorial Current (NEC) to the south and
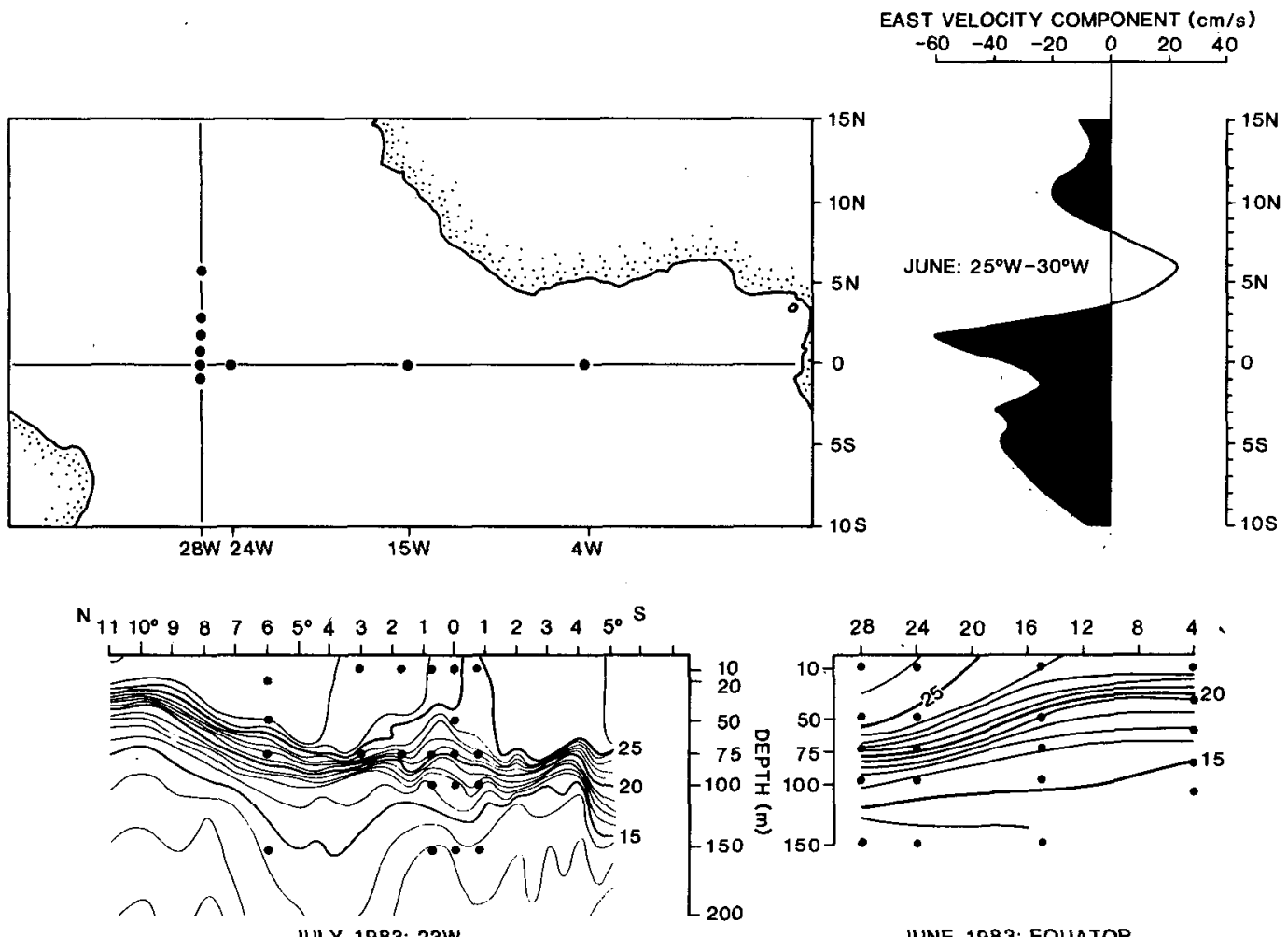

FIG. 1. SEQUAL/FOCAL current meter array in relation to the meridional distribution of the surface zonal currents and the background temperature field. The moorings are located along $28^{\circ} \mathrm{W}$ at $0.75^{\circ} \mathrm{S}, 0.75^{\circ}, 1.75^{\circ}, 3.0^{\circ}$ and $6.0^{\circ} \mathrm{N}$ and along the equator at $28^{\circ}, 24^{\circ}, 15^{\circ}$ and $4^{\circ} \mathrm{W}$. The surface zonal currents, derived from ship drift reports between $25^{\circ}$ and $30^{\circ} \mathrm{W}$ (from Richardson and Mckee 1984), are for the climatologically averaged June. The zonal temperature section is a June 1983 average from current meter data obtained along the equator between $28^{\circ}$ and $4^{\circ} \mathrm{W}$. The meridional temperature section is from a July 1983 hydrographic survey along $23^{\circ} \mathrm{W}$ by Henin et al. (1986). 
north. The June distribution is shown since it is the month when the SEC speed, meridional shear, and curvature are all maximum. The meridional temperature section is from a 3-11 July 1983 shipboard survey made along $23^{\circ} \mathrm{W}$ by Henin et al. (1986), and the zonal temperature section is a June 1983 average of current meter data obtained along the equator between $28^{\circ}$ and $4^{\circ} \mathrm{W}$. The current meters are distributed within the mixed layer and across the thermocline in which the Equatorial Undercurrent (EUC) is embedded on the equator and they bracket the region of maximum shear and curvature associated with the SEC and the EUC.

Figure 2 shows time series of the meridional velocity component sampled at $10 \mathrm{~m}$ depth from the moorings along $28^{\circ} \mathrm{W}$. Figures 3 and 4 show time series of the meridional velocity component and temperature, sampled at $10 \mathrm{~m}$ depth from the moorings along the equator. All of these time series have been low-pass filtered to remove tidal and higher frequency variability using a 49-hour Gaussian filter with a half-power point of 2.5 days. Distinctive wave packets, consisting of two to three oscillations with peak amplitudes of from 50$75 \mathrm{~cm} \mathrm{~s}^{-1}$, appear around May of 1983 and 1984 at all locations except $6^{\circ} \mathrm{N}, 4^{\circ} \mathrm{W}$. In both years these oscillations have a central periodicity of 25 days and they

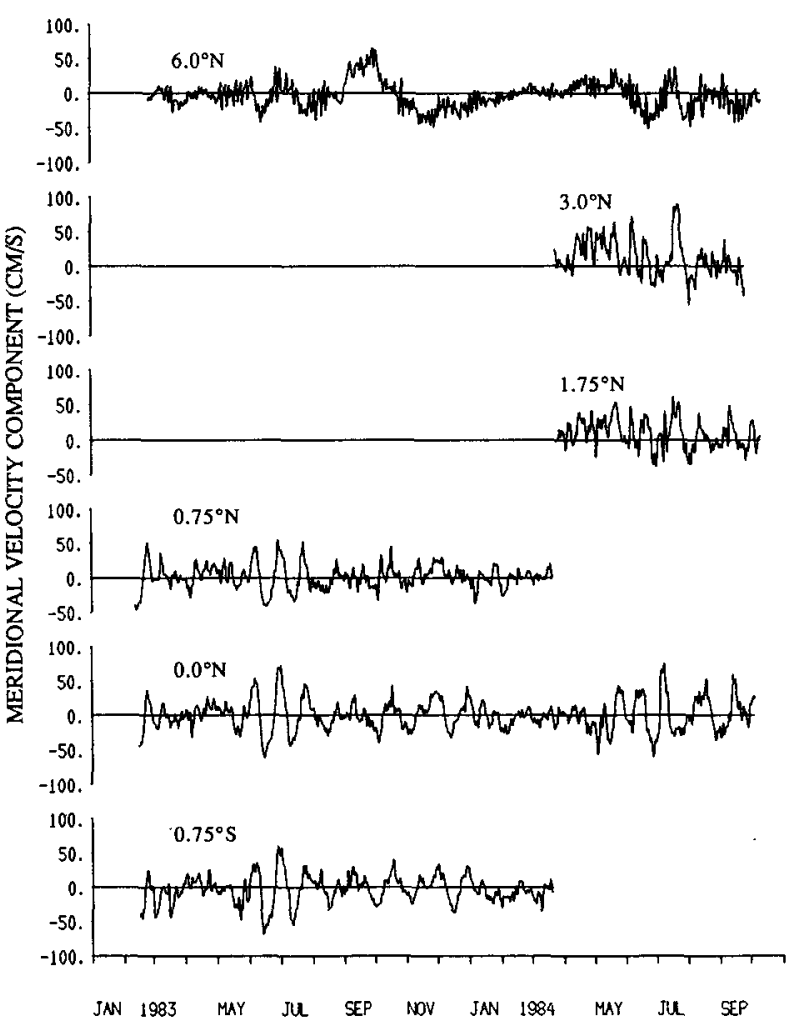

FIG. 2. Time series of the low-pass filtered meridional component of velocity observed at $10 \mathrm{~m}$ depth along $28^{\circ} \mathrm{W}$. Tic marks along the time axis denote the first day of the month.

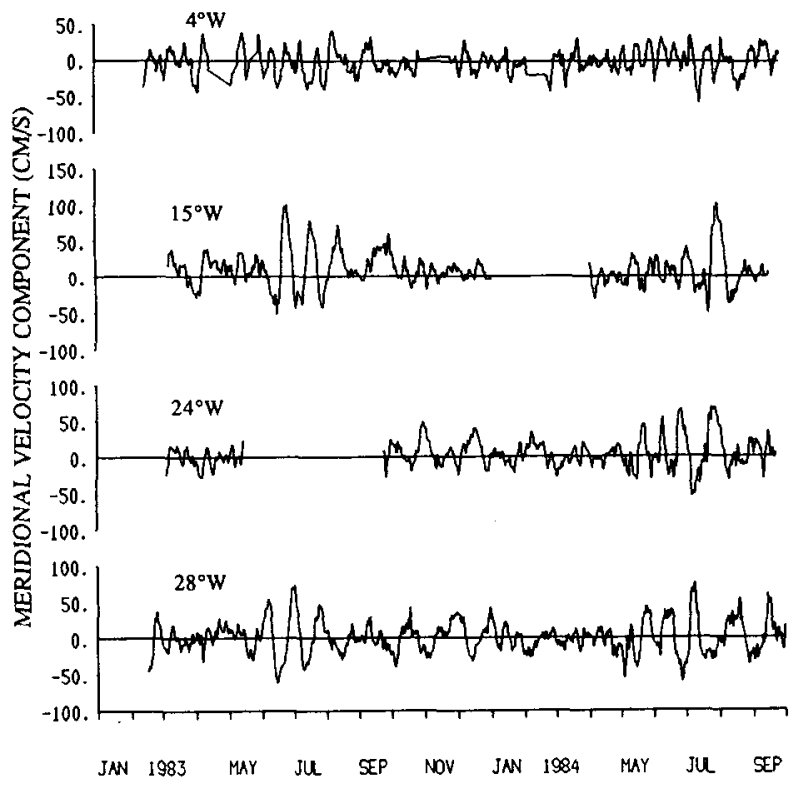

FIG. 3. Time series of the low-pass filtered meridional component of velocity observed at $10 \mathrm{~m}$ depth along the equator. Tic marks along the time axis denote the first day of the month.

commence following the springtime intensification of easterly wind stress and westward acceleration of the SEC (Weisberg et al. 1987). Although less prominent, the wave-associated oscillations are also evident in the zonal velocity component. As will be seen, these oscillations for all variables are largely attenuated with depth. The manifestations of these seasonally modu-

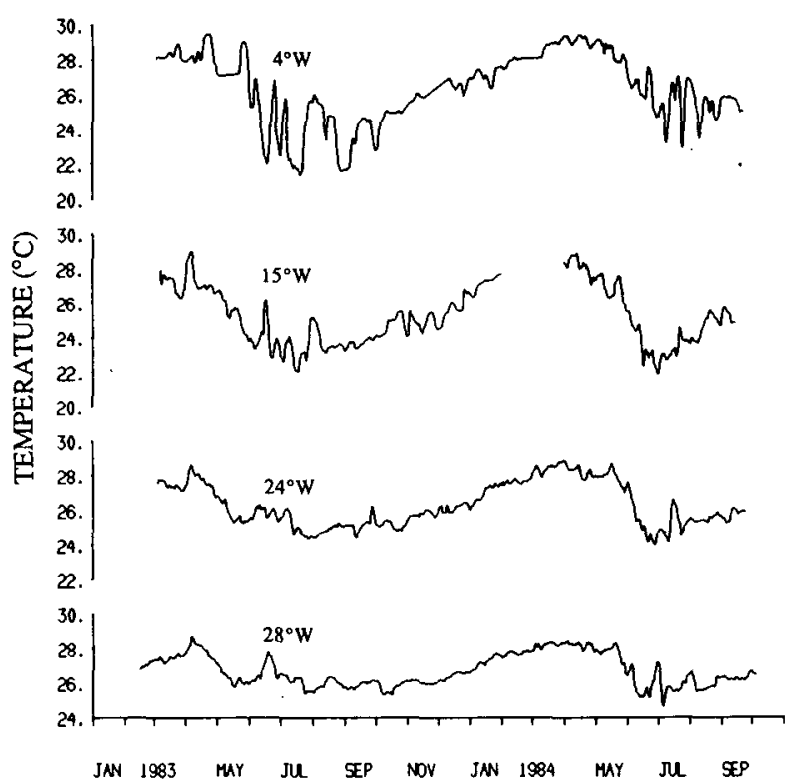

FiG. 4. Time series of the low-pass filtered temperature observed at $10 \mathrm{~m}$ depth along the equator. Tic marks along the time axis denote the first day of the month. 
lated waves upon sea surface temperature (SST-assumed equivalent to temperature at $10 \mathrm{~m}$ depth) are observed in Fig. 4. SST decreases rapidly with the onset of easterly wind stress beginning in early April 1983 and mid-May 1984. This cooling halts in both years with the appearance of the waves, fluctuations of one to two degrees ensue, and, at least in 1983 , there is a net increase in SST during the wave season. Houghton and Colin (1987) have argued that the SST fluctuations at $4^{\circ} \mathrm{W}$ are related to meridional wind stress fluctuations. However, at $28^{\circ} \mathrm{W}$ neither the velocity components nor SST are coherent with either component of the wind stress.

Weisberg (1984) employed frequency domain empirical orthogonal function (EOF) analyses on the velocity components observed from February through September 1983 to describe the structure and propagation of the wave packet during that year. For comparison these analyses are repeated independently for data spanning March through September 1984. The EOFs were computed with a central frequency and bandwidth of $1.667 \times 10^{-3}$ and $1.833 \times 10^{-3} \mathrm{cph}$, respectively. Eigenvectors and eigenvalues were calculated from the matrix of cross-spectral estimates, each computed with 15 degrees of freedom. The matrix was constructed using all pairs of time series spanning the array meridionally along $28^{\circ} \mathrm{W}$ between the equator and $3^{\circ} \mathrm{N}$, zonally along the equator between $28^{\circ}$ and $4^{\circ} \mathrm{W}$, and vertically between 10 and $75 \mathrm{~m}$ (a total of 15 time series).

The first mode accounts for $64 \%$ of the total variance in the meridional velocity component. Figure 5a shows the phase of this mode as a function of zonal separation at the different depths. Linear least squares regression of phase on zonal separation yields a zonal wavenumber estimate of $-5.3 \times 10^{-3} \mathrm{rad} \mathrm{km}^{-1}(1190 \mathrm{~km}$ wavelength) and an associated phase speed of $-55 \mathrm{~cm} \mathrm{~s}^{-1}$. These 1984 estimates can be compared with the 1983 estimates of $-5.5 \times 10^{-3} \mathrm{rad} \mathrm{km}^{-1}$ for wavenumber (1140 km wavelength) and $-53 \mathrm{~cm} \mathrm{~s}^{-1}$ for phase speed. The agreement on wavenumber between the independently calculated 1983 and 1984 results are well within the $95 \%$ confidence limits for random errors calculated from coherence and phase between $28^{\circ}$ and $24^{\circ} \mathrm{W}$ in either year of approximately $\pm 1.0 \times 10^{-3} \mathrm{rad} \mathrm{km}^{-1}$. The modal amplitudes, while not shown, are largest at $10 \mathrm{~m}$ and decrease by at least a factor of two by $75 \mathrm{~m}$ depth at $28^{\circ}, 24^{\circ}$ and $15^{\circ} \mathrm{W}$. In contrast, amplitudes at $4^{\circ} \mathrm{W}$ are uniformly small at all depths. Figure $5 \mathrm{~b}$ shows the phase of the first mode as a function of meridional separation at the available depths of 10 and $75 \mathrm{~m}$. Phase increases uniformly from the equator to $3^{\circ} \mathrm{N}$ at both depths and linear least squares regression of phase on meridional separation yields a meridional wavenumber estimate of $7.0( \pm 4.1) \times 10^{-3} \mathrm{rad} \mathrm{km}^{-1}$ ( $850 \mathrm{~km}$ wavelength) where the $95 \%$ confidence interval for random errors are estimated from nearest neighbors coherence at $10 \mathrm{~m}$ depth. Comparable data

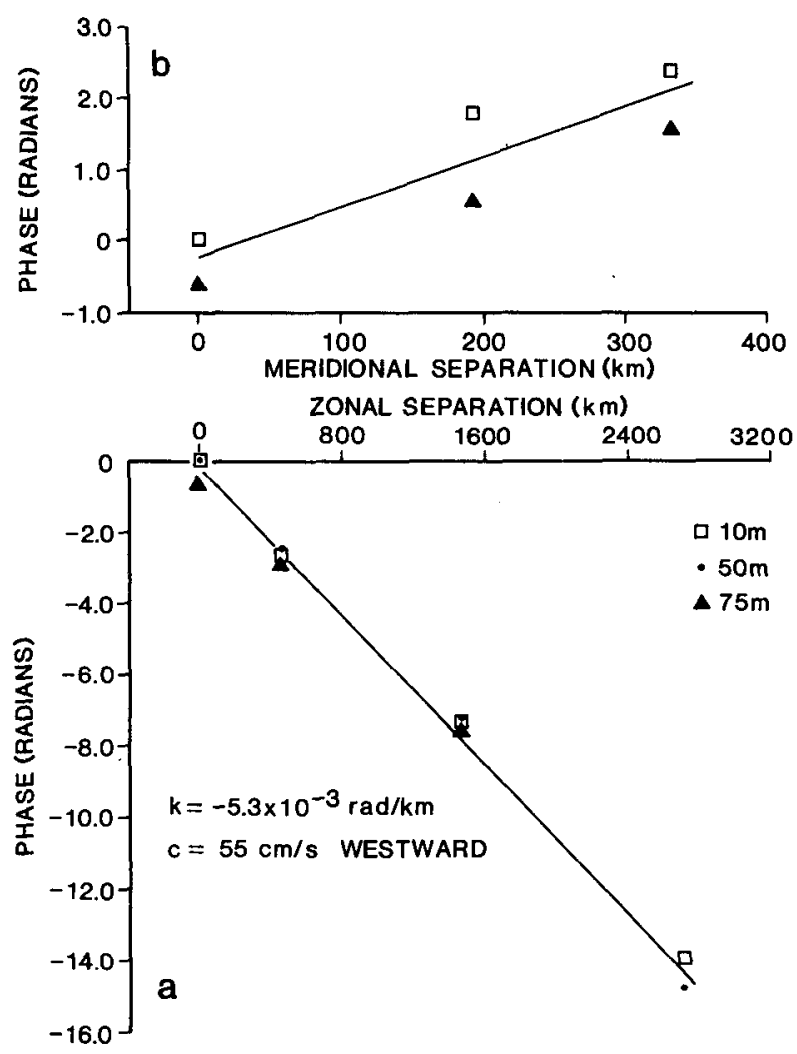

FIG. 5. Phase of the first EOF mode as a function of (a) zonal separation and (b) meridional separation. The EOFs were computed at all depths between 10 and $75 \mathrm{~m}$ for the period 1 April 1984 to 23 September 1984.

are not available for 1983. The uniform variations of phase with latitude at both depths, while only marginally significant, suggests meridional wave propagation as opposed to a meridional mode. Note that the phase at $75 \mathrm{~m}$ consistently leads that at $10 \mathrm{~m}$ at all locations and that the phase difference between 10 and $75 \mathrm{~m}$ is larger off the equator than on the equator. While these differences are not significant at the $95 \%$ level they suggest an upward phase propagation with larger vertical wavenumber component off the equator than on the equator.

\section{Perturbation energies and fluxes}

Autospectra of the meridional velocity component time series in the vicinity of the equator show a well defined peak centered upon 25-day periodicity as do the cospectra between the horizontal velocity components and between these components and temperature. In order to explore the temporal and spatial variations of these fluctuations 25-day running averages were performed to calculate means, variances, and covariances for the three velocity components and temperature. Vertical velocity is determined by vertically integrating the equation of continuity down from the surface using a rigidlid approximation. 


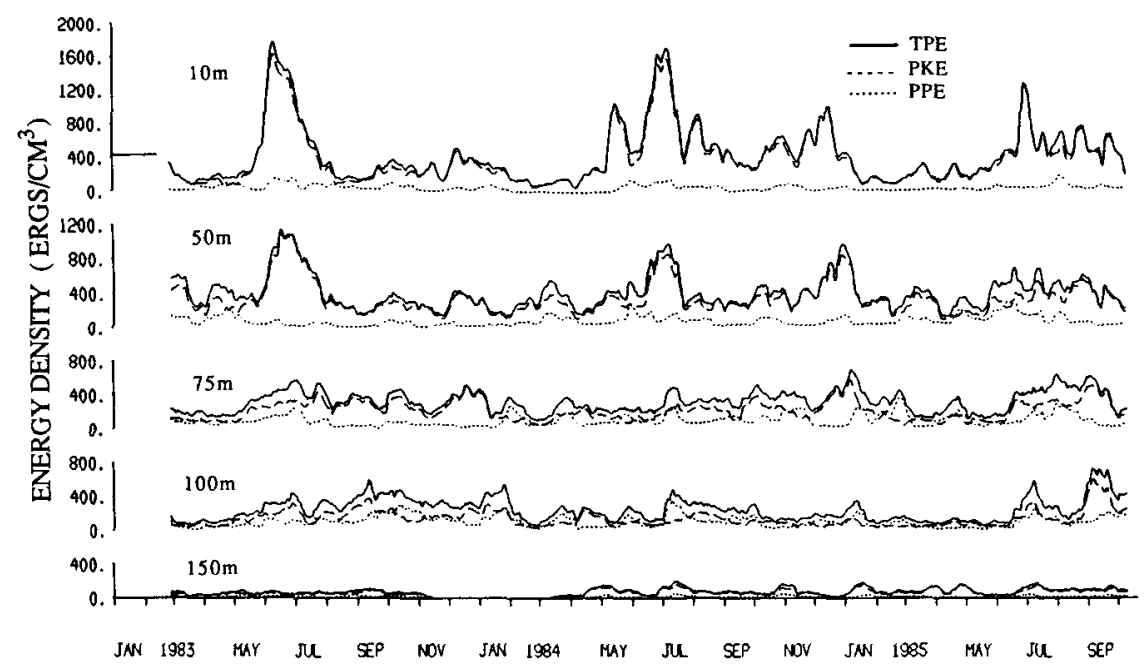

FIG. 6. Time series of perturbation kinetic energy (PKE as denoted by the dashed line), perturbation potential energy (PPE as denoted by the dotted line) and their sum, the total perturbation energy (TPE as denoted by the solid line) on the equator at $28^{\circ} \mathrm{W}$ at depths of 10 to $150 \mathrm{~m}$. The horizontal line originating from the ordinate of the $10 \mathrm{~m}$ time series indicates the background TPE level $\left(420 \mathrm{erg} \mathrm{cm}^{-3}\right)$ defined as two standard deviations above the mean TPE computed over the period of 15 August 1983 through 15 April 1984. Tic marks along the time axis denote the first day of the month.

\section{a. Perturbation energies}

Figure 6 shows perturbation energy time series at depths between 10 and $150 \mathrm{~m}$ for the 2.7 years of data at $0^{\circ} \mathrm{N}, 28^{\circ} \mathrm{W}$. Total perturbation energy (TPE) is defined as the sum of the perturbation horizontal kinetic energy $\left(\mathrm{PKE}=\rho_{0}\left(\left\langle u^{\prime} u^{\prime}\right\rangle+\left\langle v^{\prime} v^{\prime}\right\rangle\right) / 2\right)$ and the perturbation potential energy $\left(\mathrm{PPE}=g\left\langle{\rho^{\prime}}^{2}\right\rangle / 2\left|\rho_{0 z}\right|\right)$ where the angle brackets, used for variances and covariances, denote an average over 25 days and the primes denote deviations of the individual variables about their 25-day averages. For PPE, $g$ is gravity and $\rho$ is density as determined from equatorial Atlantic $T /$ $S$ relationships described by Weisberg and Weingartner (1986). The mean density is $\rho_{0}$ and the mean vertical density gradient is $\rho_{0 z}$. The vertical derivatives here and elsewhere are estimated by central differences for depths between 50 and $150 \mathrm{~m}$ and, by forward differences between $10 \mathrm{~m}$ and the next shallowest depth (either 50 or $75 \mathrm{~m}$ ) for $10 \mathrm{~m}$ depth.

At 10 and $50 \mathrm{~m}$ depths perturbation energies are strongly modulated in time, increasing in June, coincident with the appearance of the instability waves, and then decreasing to a nominal background level. As used throughout this paper, the background level of a particular quantity is defined as two standard deviations above its mean during the nonwave season of 15 August 1983 through 15 April 1984 (or 8 March 1984 depending on the available data). The differences in both TPE and PKE between the wave season and the background levels are about fivefold. In 1983, the increase in TPE from the background level of about $400 \mathrm{erg} \mathrm{cm}^{-3}$ in late May to the peak of $1800 \mathrm{erg} \mathrm{cm}^{-3}$ in early June suggests an $e$-folding growth time of about two weeks in agreement with previous modeling studies. Below $50 \mathrm{~m}$, perturbation energies decrease rapidly with depth and do not show a distinct seasonal modulation. The partition between PKE and PPE also varies with depth. Near surface TPE is predominantly kinetic with PPE rarely exceeding $150 \mathrm{erg} \mathrm{cm}^{-3}$. Within the thermocline (from 75 to $100 \mathrm{~m}$ ) the perturbation energy is more equally partitioned between PKE and PPE.

These time series also show interannual variations. In spring 1983 the perturbations arise rapidly in two to three weeks and then decline steadily over the next month. A similarly rapid development, with equivalent magnitudes, is observed in spring 1984 but the decline thereafter is not monotonic as in 1983. Instead, energy levels increase and decrease through the summer and show a secondary maximum in the fall before returning to background levels. In 1985 perturbation energies were lower than those in the two preceding years.

The horizontal distribution of perturbation energies at $10 \mathrm{~m}$ depth (the depth where these energies are largest) along $28^{\circ} \mathrm{W}$ and along the equator are shown in Figs. $7 \mathrm{a}$ and $7 \mathrm{~b}$, respectively. Figure $7 \mathrm{a}$ shows that TPE is a maximum on the equator during the wave season. During 1983 TPE is symmetrically distributed about this equatorial maximum. During 1984 TPE decreases monotonically from the equator to $6^{\circ} \mathrm{N}$ where the values do not exceed the background levels observed on the equator. Although TPE and PKE both decrease poleward from the equator, PPE is maximum at $1.75^{\circ} \mathrm{N}$. This is the approximate location of the climatological SST front separating the SEC from the 

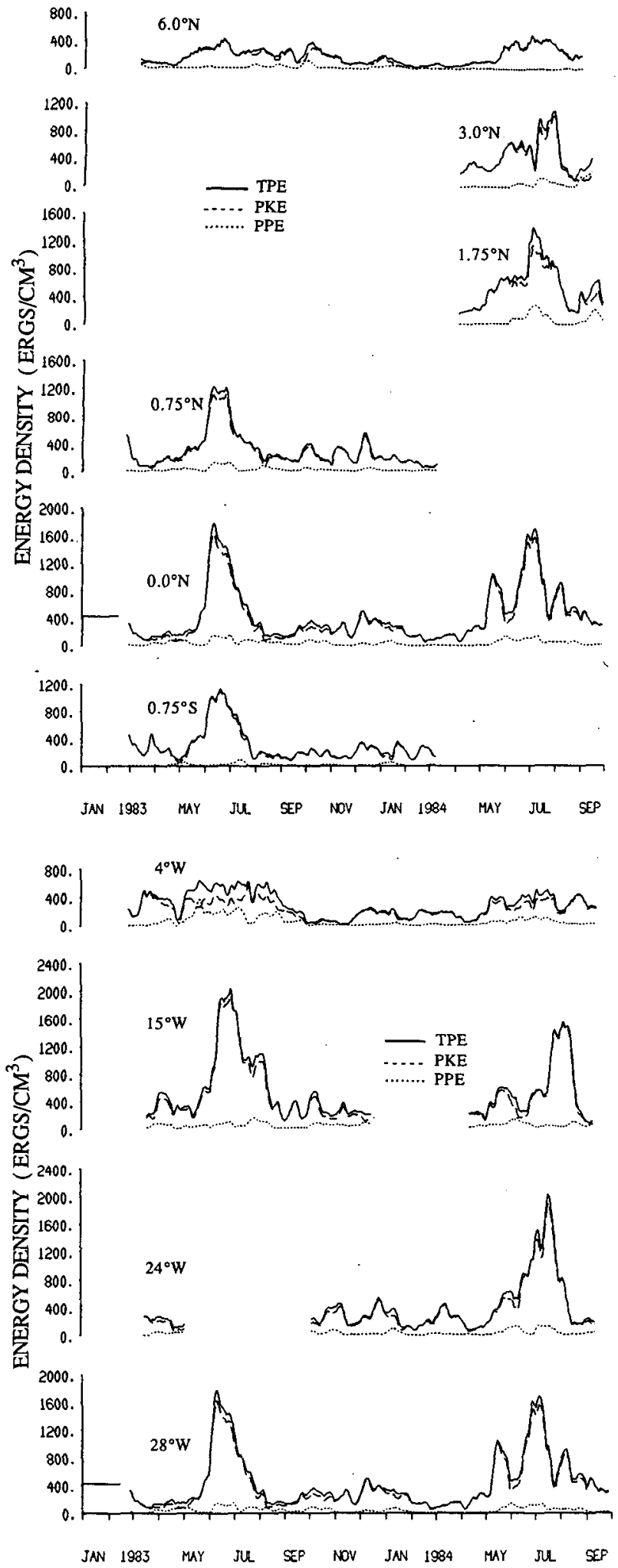

FIG. 7. Time series of PKE, PPE, and their sum, TPE, at $10 \mathrm{~m}$ depth for the moorings (a): top along $28^{\circ} \mathrm{W}$ and (b): bottom along the equator. The indicated background level at the equator is the same as in Fig. 6. Tic marks along the time axis denote the first day of the month.
NECC which would account for the increase in PPE and the prominence of instability waves observed north of the equator in satellite infrared imagery (Legeckis et al. 1983). Along the equator Fig. $7 \mathrm{~b}$ shows that perturbation energies have similar magnitudes between $28^{\circ}$ and $15^{\circ} \mathrm{W}$ but these magnitudes are much lower at $4^{\circ} \mathrm{W}$.

In combination Figs. 6 and 7a, b show that the perturbation energies, defined by 25 -day running averages, are seasonally modulated, surface confined, and horizontally inhomogeneous with maximum values on the equator extending eastward at least as far as $15^{\circ} \mathrm{W}$ but not as far $4^{\circ} \mathrm{W}$.

\section{b. Horizontal Reynolds stress, $\rho_{0}\left\langle u^{\prime} v^{\prime}\right\rangle$}

The seasonal variation of the Reynolds stress, $\rho_{0}\left\langle u^{\prime} v^{\prime}\right\rangle$, at $10 \mathrm{~m}$ depth along $28^{\circ} \mathrm{W}$ and along the equator are shown in Figs. $8 \mathrm{a}$ and $8 \mathrm{~b}$, respectively. Both figures show that $\rho_{0}\left\langle u^{\prime} v^{\prime}\right\rangle$ has the same seasonal modulation as the perturbation energies. Figure 8 a shows that during the 1983 wave season $\rho_{0}\left\langle u^{\prime} v^{\prime}\right\rangle$ is maximum on and symmetric about the equator attaining values of $1500 \mathrm{erg} \mathrm{cm}^{-3}$ and decreasing by nearly $50 \%$ within \pm 0.75 degrees. A similar peak is observed on the equator during the 1984 wave season however at $1.75^{\circ}$ and $3^{\circ} \mathrm{N}$ values of $\rho_{0}\left\langle u^{\prime} v^{\prime}\right\rangle$ are never above background. The composite meridional distribution of $\rho_{0}\left\langle u^{\prime} v^{\prime}\right\rangle$, from both years mirrors closely, both in magnitude and location, that obtained from zonally averaged surface drifter data from the equatorial Pacific Ocean by HP. Figure $8 \mathrm{~b}$ shows that $\rho_{0}\left\langle u^{\prime} v^{\prime}\right\rangle$ attains nearly uniform values along the equator between $28^{\circ}$ and $15^{\circ} \mathrm{W}$ but is never above background at $4^{\circ} \mathrm{W}$. Note that the maximum in $\rho_{0}\left\langle u^{\prime} v^{\prime}\right\rangle$ during the wave seasons of both years occurs first at $28^{\circ} \mathrm{W}$ and progressively later at $24^{\circ}$ and $15^{\circ} \mathrm{W}$. The lag between $28^{\circ}$ and $15^{\circ} \mathrm{W}$ is approximately two weeks in 1983 and four weeks in 1984 . A similar eastward progression in maximum TPE is also evident in Fig. 6. Weisberg (1984) suggested that this apparent eastward energy flux is due to an eastward progressing instability. The PHP numerical model study shows similar results.

\section{c. Meridional, $\left\langle v^{\prime} T^{\prime}\right\rangle$, and zonal, $\left\langle u^{\prime} T^{\prime}\right\rangle$, Reynolds heat flux proportionals}

Time series of the meridional component of the Reynolds heat flux proportional, $\left\langle v^{\prime} T^{\prime}\right\rangle$, along $28^{\circ} \mathrm{W}$ are shown in Fig. 9. As with the other perturbation fluxes this flux component is maximum at $10 \mathrm{~m}$ depth. It is also seasonally modulated with maximum southward values rising fivefold above the background level during the wave season. During the 1983 and 1984 wave seasons fluxes of about $-20 \mathrm{~cm}^{\circ} \mathrm{C} \mathrm{s}^{-1}$ are observed on the equator. During 1983, the magnitude of $\left\langle v^{\prime} T^{\prime}\right\rangle$ increases monotonically from $0.75^{\circ} \mathrm{S}$ to $0.75^{\circ} \mathrm{N}$ implying a convergence of heat upon the equator. The composite distribution of $\left\langle v^{\prime} T^{\prime}\right\rangle$ over both years shows 


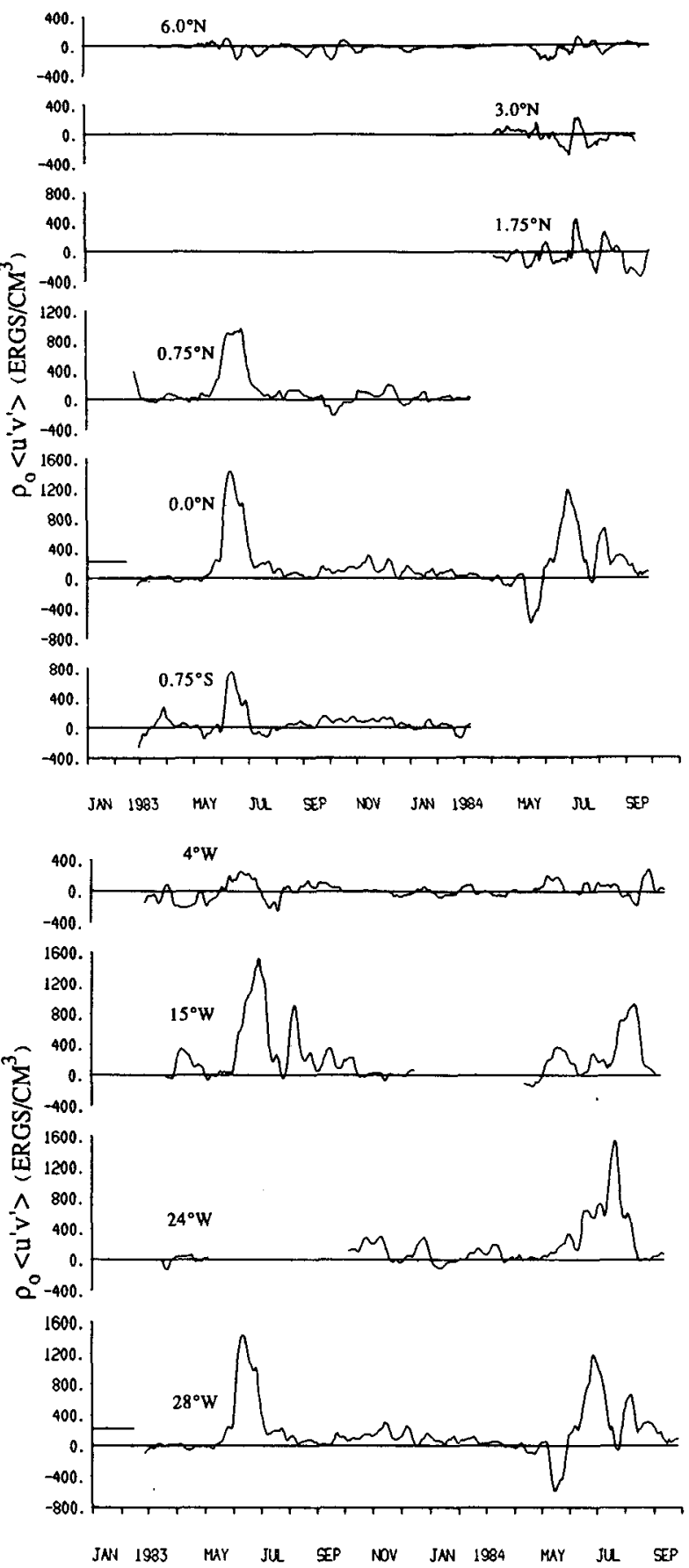

FIG. 8. Time series of the off-diagonal horizontal Reynolds' stress term, $\rho\left\langle u^{\prime} v^{\prime}\right\rangle$, at $10 \mathrm{~m}$ depth for the moorings (a) along $28^{\circ} \mathrm{W}$ and (b) along the equator. The indicated background level at $10 \mathrm{~m}$ depth on the equator at $28^{\circ} \mathrm{W}$ is $220 \mathrm{erg} \mathrm{cm}{ }^{-3}$. Tic marks along the time axis denote the first day of the month.

a banded pattern of latitudinal convergence and divergence along $28^{\circ} \mathrm{W}$ between the equator and $3^{\circ} \mathrm{N}$. In contrast to the other latitudes shown $\left\langle v^{\prime} T^{\prime}\right\rangle$ at $6^{\circ} \mathrm{N}$ is never appreciably different from zero. The meridional distribution of $\left\langle v^{\prime} T^{\prime}\right\rangle$ observed in the Atlantic is similar to that shown for the Pacific by HP except that the latter has a broader latitudinal extent.

As an estimate of the instability wave induced crossequatorial heat flux vertical integrals of $\left\langle v^{\prime} T^{\prime}\right\rangle$ to 50 $m$ depth were calculated at each equatorial mooring location and these were then zonally integrated between $28^{\circ}$ and $4^{\circ} \mathrm{W}$. The seasonal modulation of these fluxes is identical to that shown for $10 \mathrm{~m}$ in Fig. 9. In 1983 a vertically integrated heat flux of about $-3 \times 10^{7} \mathrm{~W}$ $\mathrm{m}^{-1}$ (fivefold above background) is found uniformly between $15^{\circ}$ and $28^{\circ} \mathrm{W}$. In 1984 the values at $28^{\circ} \mathrm{W}$ are the same but those at $24^{\circ}$ and $15^{\circ} \mathrm{W}$ are smaller. During both years the values at $4^{\circ} \mathrm{W}$ are the smallest $\left(-1 \times 10^{7} . \mathrm{W} \mathrm{m}^{-1}\right)$ and have a broader temporal distribution. During the instability wave season peak values of the vertically and zonally integrated heat flux approach $-0.1 \mathrm{PW}\left(1 \mathrm{PW}=10^{15}\right.$ watts $)$ in 1983 and $-0.06 \mathrm{PW}$ in 1984 . These values are underestimates since the PHP numerical model shows that the wave domain extends further west to about $40^{\circ} \mathrm{W}$. Also the vertical extent of $\left\langle v^{\prime} T^{\prime}\right\rangle$ increases to the west along with mixed layer depth. If $\left\langle v^{\prime} T^{\prime}\right\rangle$ at $28^{\circ} \mathrm{W}$ is representative of values further west then the zonally integrated meridional heat flux due to the waves may be as large as $0.2 \mathrm{PW}$ and directed southward.

Time series of $\left\langle u^{\prime} T^{\prime}\right\rangle$ at $10 \mathrm{~m}$ depth also show a seasonal modulation. During the 1983 and 1984 wave seasons $\left\langle u^{\prime} T^{\prime}\right\rangle$ is westward at all locations (except $6^{\circ} \mathrm{N}$

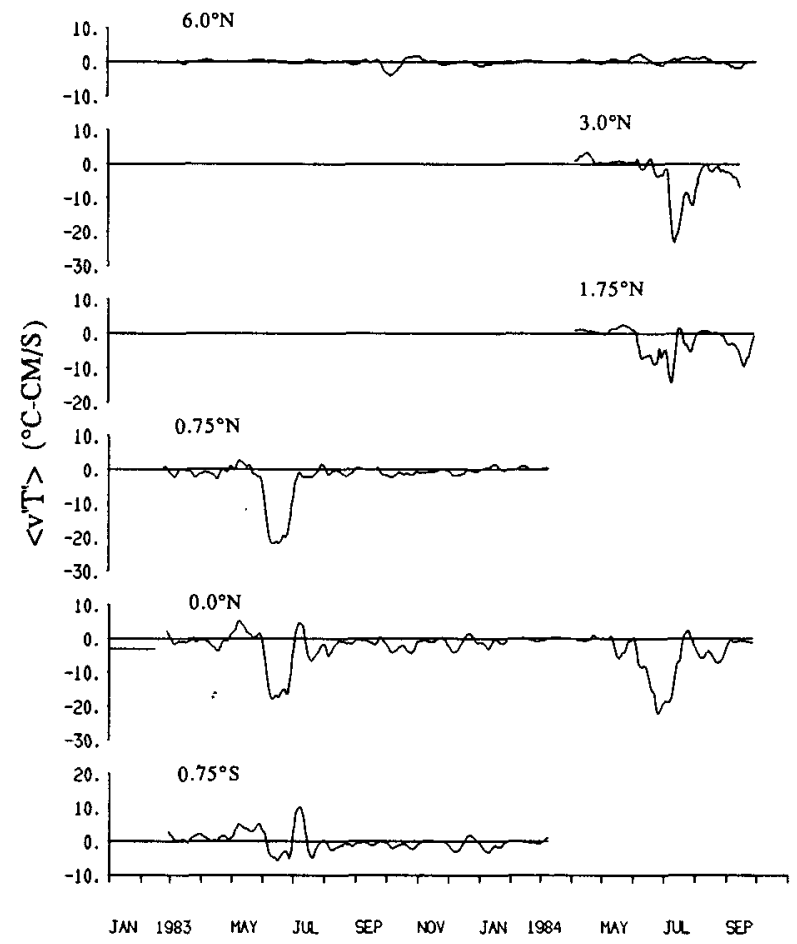

FIG. 9. Time series of the meridional Reynolds heat flux proportional, $\left\langle v^{\prime} T^{\prime}\right\rangle$, at $10 \mathrm{~m}$ depth for the moorings along $28^{\circ} \mathrm{W}$. The indicated background level for the equatorial mooring is $-3^{\circ} \mathrm{C} \mathrm{cm}$ $\mathrm{s}^{-1}$. Tic marks along the time axis denote the first day of the month. 
where it is negligible) and transports heat in the direction of the mean zonal temperature gradient. Along $28^{\circ} \mathrm{W},\left\langle u^{\prime} T^{\prime}\right\rangle$ is maximum at $1.75^{\circ} \mathrm{N}$, with magnitudes comparable to $\left\langle v^{\prime} T^{\prime}\right\rangle$. Along the equator the sign of the $\left\langle u^{\prime} T^{\prime}\right\rangle$ divergence reverses as the instability progresses eastward such that, averaged over the wave season, the net divergence is zero. Finally, the overall pattern and magnitudes observed along $28^{\circ} \mathrm{W}$ are similar to those in the Pacific Ocean reported by HP.

\section{Energetics}

The processes which control the growth and decay of TPE may be studied by examining the terms in the perturbation energy equation. The formulation of this equation, as previously used in studies of ocean energetics (e.g., Brooks and Niiler 1977; Szabo and Weatherly 1978 ; Rossby 1987$)$, is

$$
\begin{gathered}
D_{t}\left\{\rho_{0}\left(\left\langle u^{\prime 2}\right\rangle+\left\langle v^{\prime 2}\right\rangle\right)+g\left\langle\rho^{\prime 2}\right\rangle /\left|\rho_{0 z}\right|\right\} / 2= \\
-\rho_{0}\left\{\left\langle u^{\prime} u^{\prime}\right\rangle U_{x}+\left\langle u^{\prime} v^{\prime}\right\rangle\left(V_{x}+U_{y}\right)\right. \\
\left.+\left\langle v^{\prime} v^{\prime}\right\rangle V_{y}+\left\langle u^{\prime} w^{\prime}\right\rangle U_{z}+\left\langle v^{\prime} w^{\prime}\right\rangle V_{z}\right\} \\
-g\left\{\left\langle u^{\prime} \rho^{\prime}\right\rangle \rho_{0 x}+\left\langle v^{\prime} \rho^{\prime}\right\rangle \rho_{0 y}\right\} /\left|\rho_{0 z}\right| \\
-\rho_{0}\left\{\left\langle u^{\prime}\left(u^{\prime 2}+v^{\prime 2}\right)_{x}\right\rangle+\left\langle v^{\prime}\left(u^{\prime 2}+v^{\prime 2}\right)_{y}\right\rangle\right. \\
\left.+\left\langle w^{\prime}\left(u^{\prime 2}+v^{\prime 2}\right)_{z}\right\rangle\right\} \\
-\left\{\left\langle u^{\prime} p_{x}^{\prime}\right\rangle+\left\langle v^{\prime} p_{y}^{\prime}\right\rangle+\left\langle w^{\prime} p_{z}^{\prime}\right\rangle\right\}
\end{gathered}
$$

where subscripted variables denote partial differentiation and capitalized variables are 25-day running means. The left-hand term (line 1a) is the material rate of change of TPE following the mean flow. The right-hand side describes the production and redistribution of TPE within the material volume. Perturbation energy is produced as a consequence of Reynolds stresses acting on the mean sheared flow (line $1 \mathrm{~b}$ ) and by the conversion of available potential energy (APE) of the mean density field by the perturbation buoyancy fluxes (line 1c). Perturbation energy is redistributed by advection of PKE due to the perturbations themselves (line 1d) and by pressure work (line 1e). Neglected are terms describing the advection of PPE by the perturbations, terms quadratic in $w^{\prime}$, and dissipation.

\section{a. Change in energy following the mean flow: Line la}

The local rate of change of TPE dominates the total derivative. In 1983 growth occurs over a 3-week period beginning in mid-May and peaks within two weeks at about $2 \times 10^{-3} \mathrm{erg} \mathrm{cm}^{-3} \mathrm{~s}^{-1}$ before decaying at lesser rates through the end of July (see Fig. 12).

\section{b. Energy conversion by Reynolds stresses acting on the mean flow: Line $1 b$}

A material volume, acted upon by Reynolds stresses, experiences a bulk acceleration and a deformation. The deformation work represents an energy conversion between the mean sheared flow and the perturbations within the material volume. This mechanism couples the mean and turbulent energy equations for a homogeneous fluid and it forms the basis for barotropic instability (e.g., Tennekes and Lumley 1972). Figure 10 shows the temporal evolution 'of the horizontal terms in the deformation work tensor as a function of latitude along $28^{\circ} \mathrm{W}$. The latitude band above each time series denotes the mooring pair used to compute the mean velocity shear. The Reynolds stress multiplying that shear is from the equator except for the mooring pair between $1.75^{\circ}$ and $3^{\circ} \mathrm{N}$ where the Reynolds stress at $1.75^{\circ} \mathrm{N}$ is used. For clarity, the zonal terms are shown for 1984 only. In 1983 they were calculable only for the late winter and fall and were negligible.

The lead term in the deformation work tensor is $-\rho_{0}\left\langle u^{\prime} v^{\prime}\right\rangle U_{y}$. It rises sharply above the background level at all locations between $0.75^{\circ} \mathrm{S}$ and $1.75^{\circ} \mathrm{N}$ with the region of maximum growth rate $\left(4 \times 10^{-3} \mathrm{erg} \mathrm{cm}^{-3}\right.$ $\mathrm{s}^{-1}$ ) lying between the equator and $0.75^{\circ} \mathrm{N}$ where both $\left\langle u^{\prime} v^{\prime}\right\rangle$ and the meridional shear of the zonal velocity component have largest magnitudes. In comparison

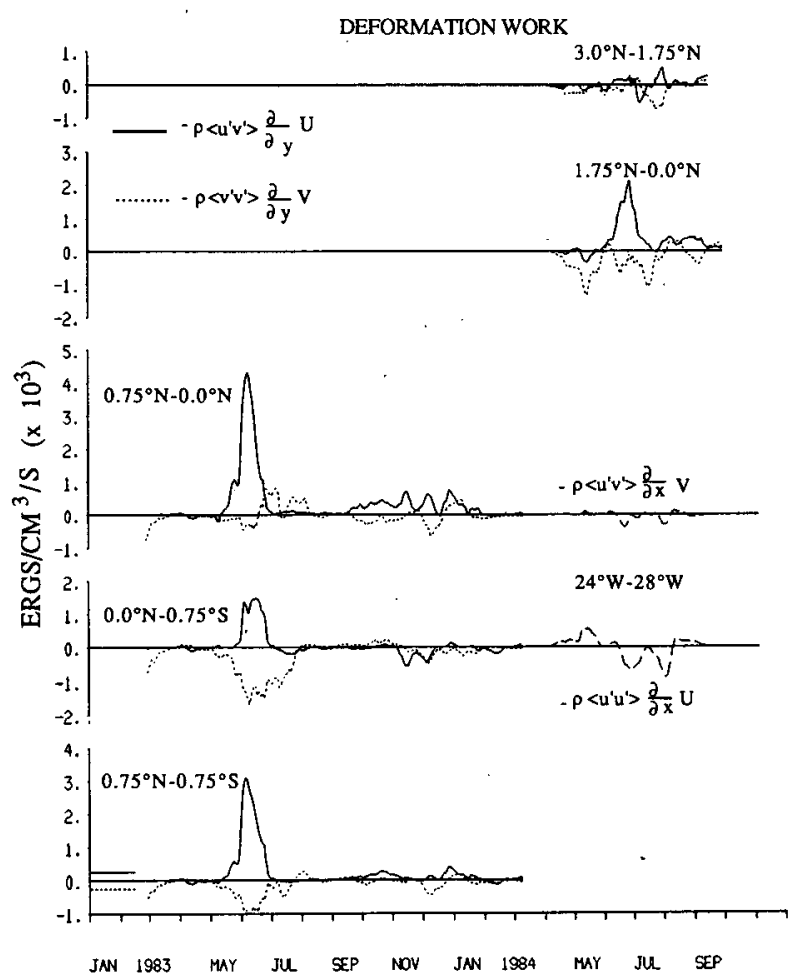

FIG. 10. Time series of terms comprising the deformation work tensor at $10 \mathrm{~m}$ depth. The latitude range for each indicates the mooring pair used to estimate the meridional velocity gradient. The zonal velocity gradients are computed between the equatorial moorings at $28^{\circ}$ and $24^{\circ} \mathrm{W}$. The background levels for the time series based on the $0.75^{\circ} \mathrm{N}-0.75^{\circ} \mathrm{S}$ pair, are $-0.2 \mathrm{erg} \mathrm{cm}^{-3} \mathrm{~s}^{-1}\left(\times 10^{3}\right)$ for $-\rho\left\langle v^{\prime} v^{\prime}\right\rangle V_{y}$ and $0.3 \mathrm{erg} \mathrm{cm}^{-3} \mathrm{~s}^{-1}\left(\times 10^{3}\right)$ for $-\rho\left\langle u^{\prime} v^{\prime}\right\rangle U_{y}$. Tic marks along the time axis denote the first day of the month. 
production by $-\rho_{0}\left\langle u^{\prime} v^{\prime}\right\rangle U_{y}$ is only one-fourth as large between the equator and $0.75^{\circ} \mathrm{S}$ and it is negligible between $1.75^{\circ}$ and $3.0^{\circ} \mathrm{N}$.

The remaining terms in the deformation work tensor either tend to oppose production by $-\rho_{0}\left\langle u^{\prime} v^{\prime}\right\rangle U_{y}$ or are negligible. The term $-\rho_{0}\left\langle v^{\prime} v^{\prime}\right\rangle V_{y}$ has greatest magnitude between $0.75^{\circ} \mathrm{S}$ and the equator where it effectively nullifies production and it is a minimum between the equator and $0.75^{\circ} \mathrm{N}$ making this the region of maximum production. Both of the zonal shear terms also oppose production but their magnitudes are smaller than the meridional shear terms. The vertical shear terms, calculable on the equator, (not shown) are an order of magnitude less than any of the horizontal shear terms and are not above background.

In summary, the contribution to PKE by deformation work (barotropic instability) is found to be maximum at $10 \mathrm{~m}$ depth slightly north of the equator within the cyclonic shear region of the SEC. On the anticyclonic side of the SEC (i.e., the shear region between the SEC and NECC) the contribution to PKE by deformation work is not above background.

\section{c. Conversion of available potential energy to pertur- bation kinetic energy: Line Ic}

The APE of the mean density field can be a source (sink) of TPE if the perturbation buoyancy fluxes act to diminish (enhance) the mean horizontal density gradient. This process provides the energy conversions associated with baroclinic instability. As in the case of the barotropic instability terms the baroclinic instability terms rise above their background levels only during the wave season but their magnitudes do not exceed $1.0 \times 10^{-3} \mathrm{erg} \mathrm{cm}^{-3} \mathrm{~s}^{-1}$ at any location. On the equator perturbation energy increases at the expense of the mean meridional density gradient via $-g\left\langle v^{\prime} \rho^{\prime}\right\rangle \rho_{0 y} /$ $\left|\rho_{0 z}\right|$, but this production is opposed by the zonal term, $-g\left\langle u^{\prime} \rho^{\prime}\right\rangle \rho_{0 x} /\left|\rho_{0 z}\right|$.

\section{d. Advection of PKE by the perturbation velocity field: Line ld}

The individual triple product terms describing the redistribution of perturbation energy by the perturbation velocity field itself do not exceed their background levels.

\section{e. Pressure work: Line 1e}

Calculating the radiation of TPE by pressure work divergence requires knowledge of the surface zonal and meridional pressure gradients. Their estimation involves vertically integrating the upper ocean isopycnal slopes (e.g., Weisberg and Weingartner 1986) and then taking the negative of this integral at a particular reference depth where the surface pressure gradient is assumed to be compensated for by the sloping isopycnals. Climatological data suggests that the zonal pressure gradient (ZPG) is nearly zero at $150 \mathrm{~m}$ throughout most of the year. Since this is the deepest depth for which simultaneous temperature data is available at $28^{\circ}$ and $24^{\circ} \mathrm{W}$ it is chosen as the reference depth for the ZPG. However the meridional pressure gradients associated with near equator subthermocline currents are quite strong at $150 \mathrm{~m}$ (Cochrane et al. 1979) which precludes choosing this depth as a reference level for the meridional pressure gradient. Merle and Arnault (1985) examined the seasonal variability of surface dynamic topography using climatological data and found that the equatorial trough deepens rapidly from May through August. Slopes of $5 \mathrm{dyn} \mathrm{cm}$ over 1 to 2 degrees of latitude are typical at this time. Similar values are reported by Katz (1981) and Hisard and Henin (1987). The meridional baroclinic response computed from isopycnal slopes between the moorings at \pm 0.75 degrees show that these surface pressure gradients would be compensated for at depths between 50 and $75 \mathrm{~m}$. Zonal velocity component time series at $0.75^{\circ} \mathrm{N}$ during the wave season show 180 degrees out-of-phase variability between 10 and $75 \mathrm{~m}$ depths further implying a reversal in the meridional pressure gradient between these two depths. For these reasons the surface meridional pressure gradient is examined using both 50 and $75 \mathrm{~m}$ depths as reference levels.

Figure 11 shows time series of the vertical, zonal, and meridional components of the pressure work divergence computed on the equator at $28^{\circ} \mathrm{W}$. The vertical component time series is shown at $75 \mathrm{~m}$, the depth where its magnitude is observed to be a maximum. Even at this depth the vertical radiation is small and never above background. The horizontal components are shown at $10 \mathrm{~m}$ depth with the zonal component referenced to $150 \mathrm{~m}$ and the meridional component referenced to either 50 or $75 \mathrm{~m}$. During the 1983 wave season both horizontal components are observed to increase above background by about an order of magnitude with absolute values of from 2 to $4\left(\times 10^{-3} \mathrm{erg}\right.$

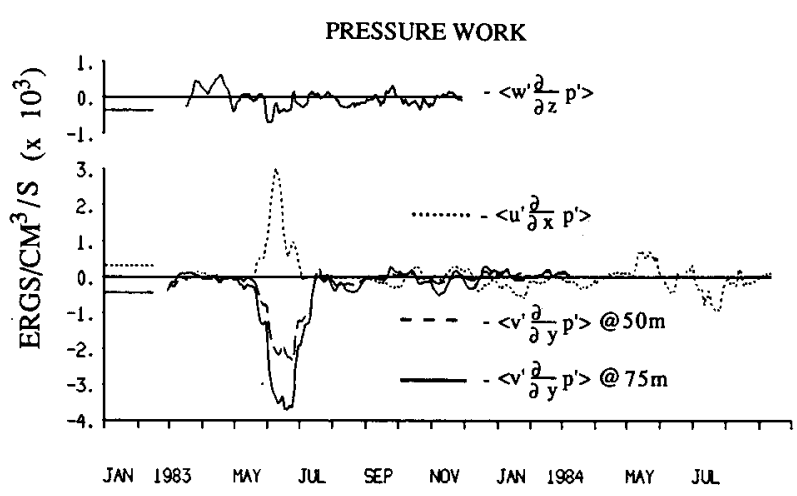

FIG. 11. Time series of the meridional, zonal, and vertical terms comprising the pressure work. The background levels for the zonal, meridional (based on a $75 \mathrm{~m}$ reference level), and vertical components are $0.3,-0.4$ and $-0.4 \mathrm{erg} \mathrm{cm}^{-3} \mathrm{~s}^{-1}\left(\times 10^{3}\right)$, respectively. Tic marks along the time axis denote the first day of the month. 
$\mathrm{cm}^{-3} \mathrm{~s}^{-1}$ ). The zonal component is convergent reaching a peak at the beginning of June and then rapidly decreasing to background values by the end of this month. In contrast the meridional component is divergent, peaking in mid-June, and then decreasing to background values in mid-July. Note that the choice of reference level affects the magnitude but not the timing of the pressure-work terms.

\section{f. Energy balance}

Time series of TPE and the processes which govern its variation, as described by Eq. (1) are shown for 1983 in Fig. 12. For each process the individual components have been calculated at $10 \mathrm{~m}$ depth on the equator at $28^{\circ} \mathrm{W}$ and summed. TPE increases rapidly from about $200 \mathrm{erg} \mathrm{cm}^{-3}$ in late May to $1800 \mathrm{erg} \mathrm{cm}^{-3}$ by the first

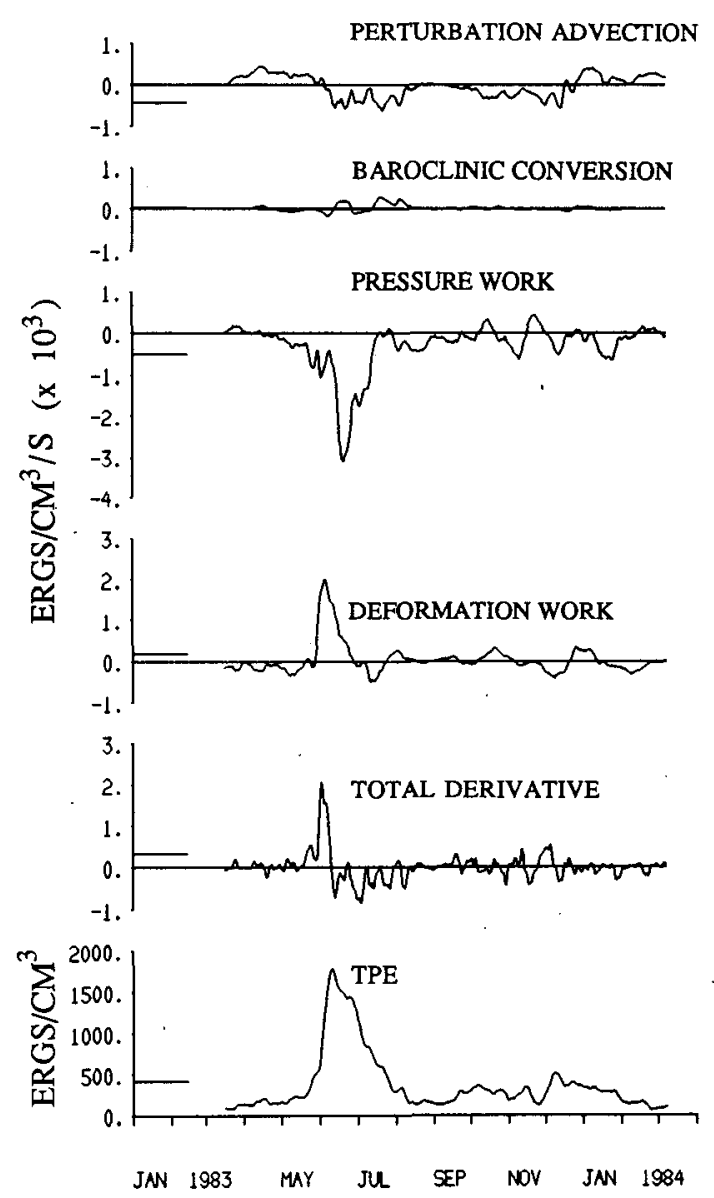

FIG. 12. Time series of TPE and the sum of components for each term comprising the perturbation energy balance equation all evaluated at $10 \mathrm{~m}$ depth on the equator at $28^{\circ} \mathrm{W}$. The background levels for TPE, the total derivative of TPE, the deformation work (barotropic instability), the pressure work (wave radiation), baroclinic instability, and perturbation advection all in units of erg $\mathrm{cm}^{-3} \mathrm{~s}^{-1}\left(\times 10^{3}\right)($ except TPE with units of $\mathrm{erg}^{-3}$ ) are $420,0.3,0.2,-0.5,0.04$ and -0.4 , respectively. Tic marks along the time axis denote the first day of the month. week of June before returning, more slowly, to background levels by the end of July. The material rate of change of TPE (in which the local rate of change dominates) is accounted for primarily by deformation work (production of TPE by barotropic instability where $-\rho_{0}\left\langle u^{\prime} v^{\prime}\right\rangle U_{y}$ dominates) and pressure work (redistribution of TPE by wave radiation ). Net baroclinic production is negligible and the redistribution of TPE by perturbation advection is relatively small but systematically negative during the wave season. The onset of the increase in TPE, as reflected in the time series for its material derivative, coincides with the onset of deformation work, both peaking with the same magnitude (about $2 \times 10^{-3} \mathrm{erg} \mathrm{cm}^{-3} \mathrm{~s}^{-1}$ ) and at the same time in early June. The material derivative then decreases rapidly and becomes negative while the deformation work decreases more slowly. It appears that the positive production by deformation work at this time is offset by a larger and negative radiative loss by pressure work resulting in a negative material derivative and decreasing TPE until all of the terms are once again at their background levels by the end of July.

\section{g. Errors}

The instability waves may be considered a bandlimited process for which confidence intervals on estimates of coherence and phase can be calculated assuming that the data are Gaussian distributed and stationary. This is the basis for the confidence intervals on zonal wavenumber given in section 2 . The nearly identical and independent results obtained for the zonal wavenumber estimates in the two separate wave seasons of 1983 and 1984 provide support for statistical inference based upon these confidence intervals.

Construction of confidence intervals for the terms describing the perturbation energies and fluxes and the TPE balance are more difficult because these terms are second moments, which would require fourth moments of their underlying probability density functions for statistical inference. Since these are unknown, an approach is adopted whereby a background level is defined for each time series as the mean value plus two standard deviations calculated over the nonwave season of 1983 through spring 1984. This calculation has approximately 60 degrees of freedom based upon equivalent bandwidth and record length. Comparisons are then drawn between the values observed during the wave season and these background values. If the background covariance results from the sum of variability occurring independently over different time scales, then the Central Limit Theorem implies that the background covariance distribution approaches a Gaussian distribution and the background level, as defined here, would approximate a $95 \%$ confidence level. During the wave season only the terms that are substantially above background are discussed as being important. For the case of the autocovariance time series, PKE, in which 
the velocity components may be assumed to be Gaussian, an $F$-test between the wave and nonwave seasons' variances shows that PKE during the wave season is significantly larger. This test, conservatively assuming one independent realization with two degrees of freedom (for waves with a one-octave bandwidth) during the 1983 wave season and 60 degrees of freedom during the nonwave season, requires a ratio greater than 3.2 to distinguish significantly different variances at $95 \%$ confidence. The computed ratio is 6.2 . Thus, while the error analysis cannot be approached rigorously, there is nothing subtle in distinguishing the wave from the nonwave seasons. However, while the seasonal modulation in the terms comprising the TPE balance is clear, the relationship amongst these terms in maintaining such balance must be viewed with caution. During the wave season of 1983 barotropic instability and meridional wave radiation are the dominant terms in the energy balance on the equator at $28^{\circ} \mathrm{W}$; but, there is no basis for statistical inference that this balance should obtain generally. The balance may differ spatially in any given year (for example baroclinic instability as a mechanism of production and vertical wave radiation may be important at $3^{\circ} \mathrm{N}$ ) and at least ten years of data over a broad enough region of the wave domain would be required to determine the energy balance in a statistically meaningful way.

\section{Discussion}

Climatological ship drift records (Richardson and McKee 1984) depict the SEC as a seasonally varying jetlike current with westward speeds on the order of $50 \mathrm{~cm} \mathrm{~s}^{-1}$. The SEC accelerates westward following the springtime intensification of the Southeast Trade Winds on the equator. Simultaneously, the NECC accelerates eastward as the intertropical convergence zone and associated wind stress curl distribution translate northward. These accelerations result in maximum westward speed and positive curvature $\left(U_{y y}\right)$, centered at about $2^{\circ} \mathrm{N}$, with $U_{y y}$ attaining magnitudes comparable to $\beta$, the gradient of planetary vorticity. On either side of this zonal velocity core speeds diminish rapidly giving rise to strong meridional shears of about 5 $\times 10^{-6} \mathrm{~s}^{-1}$. Figure 13 shows time series of $U_{y}$ computed along $28^{\circ} \mathrm{W}$ between the equator and $0.75^{\circ} \mathrm{N}$ in 1983 and between the equator and $1.75^{\circ} \mathrm{N}$ in 1984 . The springtime development of this strong shear, following the intensification of the zonal wind stress, is apparent in May of 1983 and June of 1984. While strong shears are observed in other months, climatologically the curvature is reduced at these times (Richardson and McKee 1984). In his stability analysis of equatorial currents with similar structure, Philander (1978) found that the most unstable perturbations had an $e$-folding time of about 2 weeks, a period of about 3 weeks and, a zonal wavelength of about $1000 \mathrm{~km}$ which are approximately as observed here.

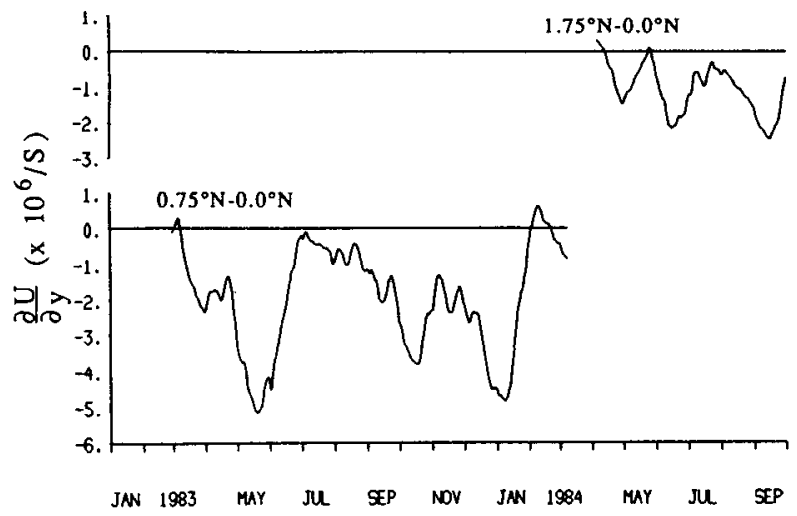

FIG. 13. Time series of the surface meridional shear of the zonal velocity component computed along $28^{\circ} \mathrm{W}$ between the equatorial mooring and the nearest mooring to the north $\left(0.75^{\circ} \mathrm{N}\right.$ in 1983 and $1.75^{\circ} \mathrm{N}$ in 1984). Tic marks along the time axis denote the first day of the month.

Observations and numerical model results for the Atlantic Ocean also agree with respect to the spatial domain and timing of the waves. Philander et al. show the instability waves to be above the thermocline and within the region $3^{\circ} \mathrm{S}$ to $5^{\circ} \mathrm{N}$, from $10^{\circ}$ to $40^{\circ} \mathrm{W}$. This is in accordance with the observed perturbation energies and fluxes which are largest within the upper 50 $\mathrm{m}$, along the equator between $28^{\circ} \mathrm{W}$ and $15^{\circ} \mathrm{W}$ but insignificant at $0^{\circ} \mathrm{N}, 4^{\circ} \mathrm{W}$ and $6^{\circ} \mathrm{N}, 28^{\circ} \mathrm{W}$. In both model and observations the waves arise in boreal summer, persist for two to four cycles and have an apparent eastward energy flux which is opposite in direction to the westward phase propagation. The observed Reynolds stress time series with peaks occurring progressively later to the east along the equator indicate that the instability itself progresses eastward.

Waves propagating across a latitudinally and vertically sheared zonal current may, under certain conditions, alter the momentum balance of the mean zonal flow. The conditions under which waves interact with such a flow were first addressed by Eliassen and Palm (1960) in their investigation of the influence of twodimensional, nonrotating, internal gravity waves upon a vertically sheared mean current. Charney and Drazin (1961) extended this line of investigation by considering the eddy transports of heat and momentum associated with vertically propagating, midlatitude, atmospheric planetary waves. Their fundamental result is that linear, inviscid, adiabatic, steady waves propagating through a sheared zonal flow, devoid of critical levels, will leave the zonally averaged flow and thermal fields unchanged. Their theorem, known as the "nonacceleration", "noninteraction" or "Charney-Drazin" theorem, was extended by Holton (1974) to the equatorial $\beta$-plane. Most applications have been with respect to the atmosphere, but recently McPhaden et al. (1986) utilized this approach to investigate the interaction of baroclinic equatorial Kelvin waves with sheared zonal 
currents. The theorem may be derived by considering quasi-geostrophic, inviscid, adiabatic flows. The basic, sheared zonal flow, $U$, is in thermal wind balance and the basic meridional flow, $V$, is in geostrophic balance. Zonal averages are taken about a latitude circle, over a zonally bounded basin with cyclic boundary conditions, or over an unbounded domain in which the disturbances are evanescent. Under these conditions terms differentiable with respect to longitude vanish as does the zonally averaged $V$. Written to the order of the Rossby number, the zonally averaged zonal momentum, heat, and continuity equations are

$$
\begin{aligned}
U_{t}-f v & =-\left(u^{\prime} v^{\prime}\right)_{y} \\
\rho_{t}+w \rho_{z} & =-\left(v^{\prime} \rho^{\prime}\right)_{y} \\
v_{y}+w_{z} & =0
\end{aligned}
$$

where the primes denote departures from zonal averages, $f$ is the Coriolis parameter, and density is assumed to be a function of temperature. If $U_{t}=0$, Eq. (2) implies that the perturbation momentum flux convergence gives rise to a northward flow by virtue of the Coriolis force. Similarly, if $\rho_{t}=0$, Eq. (3) implies that the latitudinal convergence of meridional perturbation heat flux is balanced by the vertical advection of heat. Under these conditions continuity is satisfied with $v$ $=\left[\left(v^{\prime} \rho^{\prime}\right)_{z} / \rho_{z}\right]$ and $w=-\left[\left(v^{\prime} \rho^{\prime}\right)_{y} / \rho_{z}\right]$. Mean acceleration or heating will arise to the extent that the direct wave forcing, due to the convergence of the perturbation fluxes, is not balanced by the wave-induced meridional circulation. Substituting the expression for $v$ obtained from continuity allows Eq. (2) to be rewritten as:

$$
U_{t}=-\left(u^{\prime} v^{\prime}\right)_{y}+f\left(v^{\prime} \rho^{\prime}\right)_{z} / \rho_{z}=\nabla \cdot \mathbf{F}
$$

where $\mathbf{F}$, the vector $-u^{\prime} v^{\prime} \mathbf{j}+f\left(v^{\prime} \rho^{\prime}\right) / \rho_{z} \mathbf{k}$, which lies in the meridional plane, is defined as the Eliassen-Palm or "EP-flux" vector. If $F$ is nondivergent then the wave field remains linear and steady and the mean flow is unaltered by the passage of the waves. Moreover, if the disturbance is Rossby wavelike then $F$ is parallel to the component of the group velocity which lies in the meridional plane (Pedlosky 1987, §6.14). As such, F has significant diagnostic value (e.g., Edmon et al. 1980) in that it is computable from observations and conveniently illustrates the net propagation of wave energy from one depth and latitude to another.

Andrews and McIntyre (1976) generalize this derivation on the equatorial $\beta$-plane to include wave transcience, dissipation, and excitation. Their formulation begins with the zonally averaged, primitive equations:

$$
\begin{gathered}
U_{t}+v\left(U_{y}-\beta y\right)+w U_{z}=-\left(u^{\prime} v^{\prime}\right)_{y}-\left(u^{\prime} w^{\prime}\right)_{z} \\
v_{y}+w_{z}=0 \\
\rho_{t}+v \rho_{y}+w \rho_{z}=-\left(v^{\prime} \rho^{\prime}\right)_{y}-\left(w^{\prime} \rho^{\prime}\right)_{z}
\end{gathered}
$$

They transform these equations to include a residual velocity by writing the vertical and meridional velocity components as

$$
\begin{aligned}
& w=w_{r}-\left(v^{\prime} \rho^{\prime}\right)_{y} / \rho_{z} \\
& v=v_{r}+\left(v^{\prime} \rho^{\prime}\right)_{z} / \rho_{z},
\end{aligned}
$$

where the residual velocity, denoted by the subscript $r$, is the difference between the total circulation in the meridional plane and the portion whose effects balance the convergence of perturbation heat and momentum fluxes under quasi-geostrophic conditions (Pedlosky 1987). Substituting these expressions for the meridional circulation into Eqs. (6)-(8) and rearranging, yields

$$
\begin{gathered}
U_{t}+v_{r}\left(U_{y}-\beta y\right)+w_{r} U_{z}=\nabla \cdot \mathbf{S} \\
=-\left(u^{\prime} v^{\prime}\right)_{y}+U_{z}\left(v^{\prime} \rho^{\prime}\right)_{y} / \rho_{z}-\left(u^{\prime} w^{\prime}\right)_{z} \\
-\left(U_{y}-\beta y\right)\left(v^{\prime} \rho^{\prime}\right)_{z} / \rho_{z} \\
v_{r y}+w_{r z}=0 \\
\rho_{t}+v_{r} \rho_{y}+w_{r} \rho_{z}=-\left(w^{\prime} \rho^{\prime}\right)_{z}-\left[\left(v^{\prime} \rho^{\prime}\right)_{z} / \rho_{z}\right] \rho_{y}
\end{gathered}
$$

where $\mathbf{S}$, the vector $\left(-u^{\prime} v^{\prime}+U_{z}\left(v^{\prime} \rho^{\prime}\right) / \rho_{z}\right) \mathbf{j}+\left(-u^{\prime} w^{\prime}\right.$ $\left.-\left(U_{y}-\beta y\right)\left(v^{\prime} \rho^{\prime}\right) / \rho_{z}\right) \mathbf{k}$, is the ageostrophic version of the EP flux-vector and $S$ reduces to $F$ when quasigeostrophic scaling applies. Both $\mathbf{F}$ and $\mathbf{S}$ contain all the wave-related perturbation forcings. If $\boldsymbol{\nabla} \cdot \mathbf{S}=\mathbf{0}$, then the waves have no effect upon the zonally averaged flow and the conditions of the noninteraction theorem obtain. If $\nabla \cdot \mathbf{S} \neq 0$ then the waves will alter the mean circulation.

The SEQUAL/FOCAL mooring program had insufficient coverage for determining zonal averages but, as previously noted, strong similarities in the meridional distribution of perturbation fluxes are apparent between the zonally averaged Pacific Ocean surfacedrifter data of HP and that obtained from the moorings along $28^{\circ} \mathrm{W}$. In light of these similarities the data from the moorings clustered about the equator at $28^{\circ} \mathrm{W}$ are used for estimating the EP flux vector divergence. The dominant terms comprising $\boldsymbol{\nabla} \cdot \mathbf{S}$ during the 1983 wave season come from the divergence of the meridional component of $\mathbf{S}$, i.e., the meridional convergence of Reynolds stress, $-\left(u^{\prime} v^{\prime}\right)_{y}$, and the advection of eastward momentum by the wave-induced vertical motion, $\left[\left(v^{\prime} \rho^{\prime}\right)_{y} / \rho_{z}\right] U_{z}$. Time series of these terms and their sum $(\sim \nabla \cdot \mathbf{S})$, evaluated between $0.75^{\circ} \mathrm{S}$ and the equator and between the equator and $0.75^{\circ} \mathrm{N}$, are shown in Fig. 14. The lead terms in the EP flux divergence show the same seasonal modulation as TPE and their magnitudes during the wave season exceed background levels by between twofold to tenfold. The remaining terms (not shown) are an order of magnitude smaller and are never above their background levels. North of the equator $-\left(u^{\prime} v^{\prime}\right)_{y}$ accelerates the surface current eastward, whereas south of the equator it ac- 
$b: 0.0^{\circ} \mathrm{N}-0.75^{\circ} \mathrm{S}$

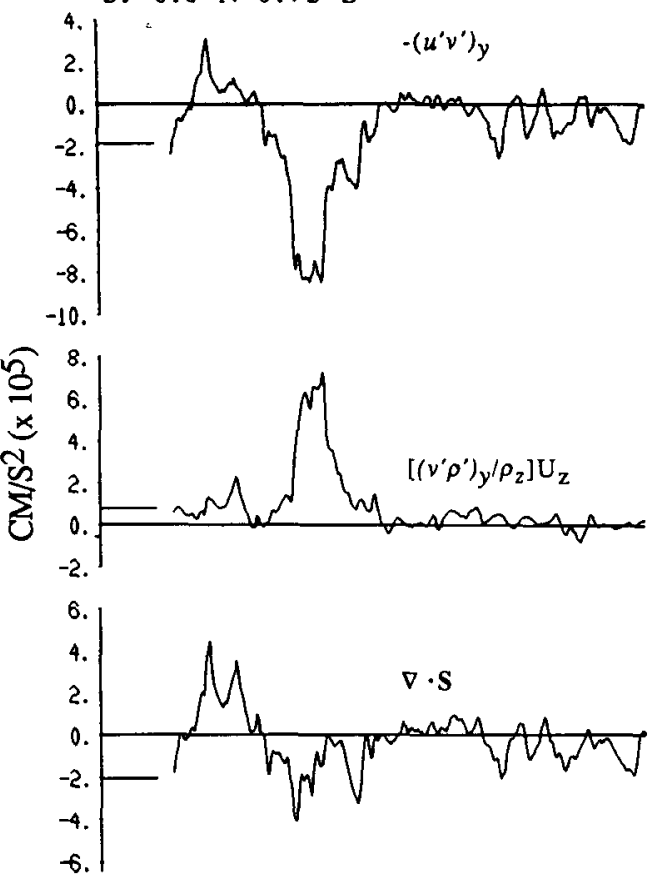

a: $0.75^{\circ} \mathrm{N}-0.0^{\circ} \mathrm{N}$

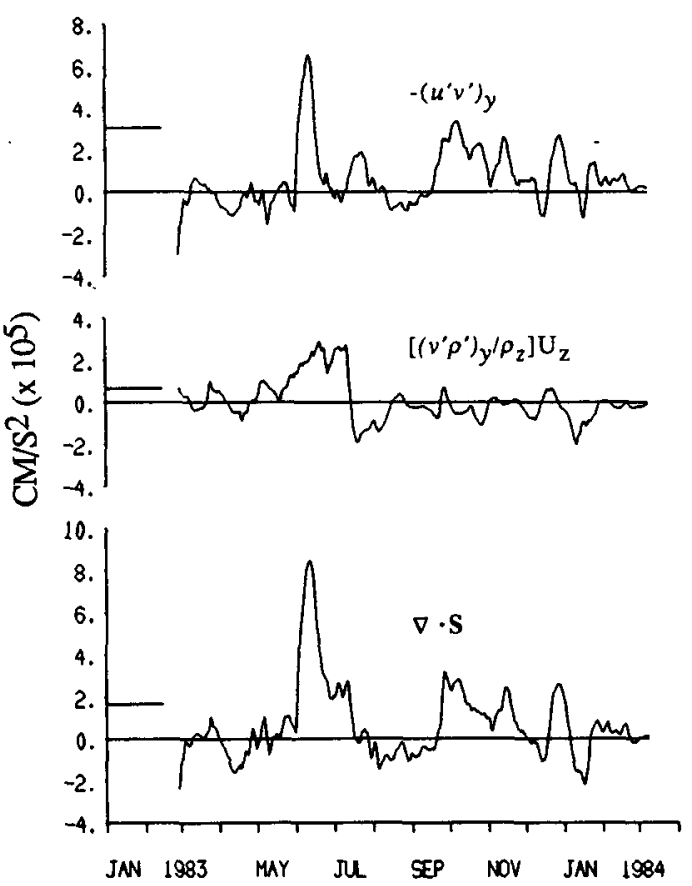

FIG. 14. Time series of the dominant terms comprising the EliassenPalm flux divergence (the meridional convergence of Reynolds stress, $-\left(u^{\prime} v^{\prime}\right)_{y}$, and the advection of eastward momentum by the waveinduced vertical motion, $\left[\left(v^{\prime} \rho^{\prime}\right)_{y} / \rho_{z}\right] U_{z}$ and their sum, $\nabla \cdot \mathbf{S}$, computed between (a) $0.75^{\circ} \mathrm{N}$ and $0.0^{\circ}$ and (b) $0.0^{\circ}$ and $0.75^{\circ} \mathrm{S}$. The background levels for $-\left(u^{\prime} v^{\prime}\right)_{y},\left[\left(v^{\prime} \rho^{\prime}\right)_{y} / \rho_{z}\right] U_{z}$, and $\nabla \cdot \mathrm{S}$ between $0.75^{\circ} \mathrm{N}$ and $0.0^{\circ}$ all in units of $\mathrm{cm} \mathrm{s}^{-2}\left(\times 10^{5}\right)$ are $3.0,0.7$ and 1.7 , respectively. The background levels for $-\left(u^{\prime} v^{\prime}\right)_{y},\left[\left(v^{\prime} \rho^{\prime}\right)_{y} / \rho_{z}\right] U_{z}$, and $\nabla \cdot \mathrm{S}$ between $0.0^{\circ} \mathrm{N}$ and $0.75^{\circ} \mathrm{S}$ all in units of $\mathrm{cm} \mathrm{s}^{-2}\left(\times 10^{5}\right)$ are $-1.9,0.8$ and $-2.0 \mathrm{~cm} \mathrm{~s}^{-2}$, respectively. Tic marks along the time axis denote the first day of the month. celerates the surface current westward. South of the equator $\left[\left(v^{\prime} \rho^{\prime}\right)_{y} / \rho_{z}\right] U_{z}$ opposes $-\left(u^{\prime} v^{\prime}\right)_{y}$ thereby decreasing its effect. North of the equator $\left[\left(v^{\prime} \rho^{\prime}\right)_{y} / \rho_{z}\right] U_{z}$ acts in concert with $-\left(u^{\prime} v^{\prime}\right)_{y}$ with the net effect of decelerating the westward flowing SEC. These wave associated accelerations, being asymmetrical about the equator, tend to reduce the meridional shear of the surface zonal currents consistent with the effects of barotropic instability. The development and disappearance of the meridional shear between the equator and $0.75^{\circ} \mathrm{N}$ (Fig. 13) during spring 1983 coincides with the wave season. Based upon the June 1983 average of $\boldsymbol{\nabla} \cdot \mathbf{S}$ the net forces per unit mass exerted by the waves on the surface currents between $0.75^{\circ} \mathrm{S}$ and the equator and between the equator and $0.75^{\circ} \mathrm{N}$ are -1.0 $\times 10^{-5}$ and $4.5 \times 10^{-5} \mathrm{dyn}^{-3}$, respectively. Distributing these forces over $50 \mathrm{~m}$ depth corresponds to an equivalent westward wind stress of $-0.05 \mathrm{dyn}^{-2}$ south of the equator and an equivalent eastward wind stress of $0.23 \mathrm{dyn}^{-2}$ north of the equator. The latter value is approximately $50 \%$ of the magnitude of the westward wind stress observed during the 1983 wave season (Colin and Garzoli 1987).

The magnitude of the divergence of the estimated EP-flux vector is consistent with the theoretical scaling arguments of Andrews and MacIntyre (1976). They show that $\nabla \cdot \mathbf{S}$ scales according to the ratio, $\eta^{\prime} \mu^{\prime} / L \tau$ where $\mu^{\prime}$ and $\eta^{\prime}$ represent scales for the perturbation velocity and meridional displacement of a material element, respectively. The variables $L$ and $\tau$ represent the meridional length scale of the disturbance and the time scale associated with wave excitation, respectively. For the waves observed in the Atlantic Ocean appropriate values for these scales are: $\mu^{\prime} \sim 50 \mathrm{~cm} \mathrm{~s}^{-1}, \eta^{\prime}$ $\sim 600 \mathrm{~km}$ (based upon $\mu^{\prime}$ and a half-wave period of 12 days), $L \sim 900 \mathrm{~km}$ and $\tau \sim 14$ days. These scales imply that in the region of wave excitation the magnitude of $\nabla \cdot \mathbf{S}$ is $\sim 2-3 \times 10^{-5} \mathrm{~cm} \mathrm{~s}^{-2}$. This agrees with the calculations shown in Fig. 14 and when interpreted as a force per unit mass has the same magnitude as the ZPG.

Satellite infrared imagery (e.g., Legeckis and Reverdin 1987) shows maximum SST variability along the front separating the SEC from the NECC. In contrast to this, the meridional distributions of the Reynolds fluxes, the TPE, and the barotropic production for the Atlantic discussed in sections 3 and 4, as well as those reported by HP for the Pacific, and as modeled for both oceans by PHP, all indicate that wave generation occurs near the equator within the cyclonic shear region of the SEC as opposed to the anticyclonic shear region between the SEC and the NECC. Furthermore, the flow in the cyclonic region is divergent whereas the flow in the anticyclonic region is convergent. Since divergence destabilizes westward jets (e.g., Philander 1978; Cox 1980) the region between the equator and the core of the SEC is expected to be a more favorable site for instability. 
Cox (1980) shows that downward propagation is the principle avenue of dispersal for instability derived wave energy while the present observations suggest that, locally, meridional wave propagation is important. The apparent discrepancy can be resolved by noting the global balance considered by Cox as opposed to the local balance presented here. The prerequisites for meridional wave radiation are that the ambient flow field possesses potential vorticity and that the Rossby-like waves must have westward phase speed relative to the ambient flow (e.g., Pedlosky 1977; Talley 1983). Since surface current speeds are eastward north of the SEC and typically less than $50 \mathrm{~cm} \mathrm{~s}^{-1}$ westward within the SEC, meridional propagation should be possible. Hence, while vertical propagation appears small right on the equator (Fig. 5), the region just to the north may be the conduit for wave radiation into the abyss. Evidence for this is given in the PHP model results which show that $\left\langle w^{\prime} T^{\prime}\right\rangle$ and its vertical derivative while small on the equator are maximum at $3^{\circ} \mathrm{N}$. The latter also implies that baroclinic production may be important in the thermocline near $3^{\circ} \mathrm{N}$.

Section 4 established causality between the instability waves' existence and the seasonally varying SEC, and the discussion thus far has shown the effects of the waves upon the SEC. Essentially barotropic instability generates the waves whose Reynolds fluxes in turn tend to remove the source of instability by decelerating the SEC to the north of the equator and reducing its cyclonic shear. In a steady state wave field a balance would be struck between wave generation and dispersion or dissipation. However, the SEC itself is a consequence of the annually varying trade winds and the associated basinwide pressure field adjustment. Equatorial $\beta$-plane model responses to switched on zonal wind stress (e.g., Hurlburt et al. 1976; Cane and Sarachik 1977; Philander and Pacanowski 1980) show that the ZPG response is to overshoot its equilibrium value with the wind stress before relaxing to it. The surface current's linear response is to rapidly accelerate westward in response to an easterly wind stress intensifcation and then to decelerate, and even reverse direction, as the ZPG overshoots. A deceleration or reversal of the SEC will be stabilizing. Specific demonstrations of the ZPG response in the Atlantic using synoptic data and a linear model are given by Weisberg and Weingartner (1986) and Weisberg and Tang (1987). These studies show that the maximum ZPG overshoot at $28^{\circ} \mathrm{W}$ occurs about three months after the winds intensify in spring. In addition to the linear response, nonlinear effects, such as the instabilities presented here, can also limit the SEC's development; however, the SEC will diminish as the ZPG strengthens even in the absence of the waves. The seasonal modulation of the instability waves in the Atlantic Ocean must therefore be considered a consequence of the basinwide adjustment of the ZPG. Differences in the seasonal evolution of the ZPG between the Atlantic and Pacific would also explain the longer duration of the wave season in the latter ocean, where waves persist for 6 to 8 months (Halpern et al. 1987) versus 2 to 3 months in the Atlantic. Owing to the greater basin width of the Pacific its equatorial ZPG response evolves over a longer time allowing conditions conducive to instability to persist longer.

Instabilities are an important source of mesoscale energy in the oceans. Away from western boundaries, midocean currents have scales larger than the internal deformation radius and baroclinic instability prevails (Gill et al. 1974). Midocean equatorial currents are an exception. Their shear scales approximate the internal deformation radius allowing barotropic instability to be favored over baroclinic instability. The results reported here for perturbation energy production rates along the equator by barotropic instability are similar in magnitude to those levels observed in western boundary currents (e.g., Szabo and Weatherly 1978, for the Kuroshio, and Brooks and Niiler 1977; Dewar and Bane 1985; Rossby 1987; Leaman et al. 1987, for the Gulf Stream system ) and the PKE levels observed on the equator during the instability-wave season are amongst the highest observed anywhere in the world's oceans as tabulated by Dickson (1983). In contrast to PKE production by barotropic instability, the production rates by baroclinic instability near the equator are an order of magnitude smaller than those observed in the Gulf Stream. However, they are still nearly an order of magnitude higher than the rates observed in other midocean regions such as the Antarctic Circumpolar Current (Bryden 1979), the Gulf Stream recirculation region (Bryden 1982), and the North Equatorial Current (Keffer 1983) and with respect to PPE alone, the values observed on the equator are the same as those reported by Dantzler (1977) for the central Atlantic's midthermocline. Given these comparisons, when viewed from the perspective of TPE production, the equatorial currents more closely resemble western boundary currents than mid-ocean currents. Furthermore, while instabilities in most ocean currents are observed to be continuous processes of energy conversion, the uniquely distinguishing feature of the equatorial Atlantic instabilities is their pronounced seasonal modulation which occurs as a consequence of the rapid annual intensification of wind stress and the basinwide adjustment time.

Along with their importance in the momentum and mechanical energy budgets, the waves also exert a significant influence on the heat balance. In a numerical simulation of the heat budget for the tropical Atlantic Ocean, Philander and Pacanowski.(1986, hereafter referred to as PP86) estimated that the annually averaged, zonally integrated heat transport by the waves is southward at about $0.1 \mathrm{PW}$. In comparison the annually averaged, cross-equatorial heat transport is northward increasing from $0.7 \mathrm{PW}$ at $5^{\circ} \mathrm{S}$ to $1.0 \mathrm{PW}$ at $2.5^{\circ} \mathrm{N}$. The wave-induced southward heat transport, derived 
from the moored array, is the same order of magnitude as in the model. While it is small relative to the total northward heat transport, the magnitude of the waveinduced heat transport is the same as the increase in northward heat transport occurring across the equator between $5^{\circ} \mathrm{S}$ and $2.5^{\circ} \mathrm{N}$. The model also shows that the majority of the cross-equatorial heat transport occurs along the western boundary where the SEC feeds into the North Brazil Current which in turn feeds into the NECC. This process occurs on an annual cycle resulting in maximum rate of heat storage along the NECC ridge during boreal summer. The timing of the wave season coincides with this period of maximum heat storage rate. In essence, the instability waves act as a thermostat; transferring the "excess" heat of the NECC southward. In the absence of the waves the storage of heat and its subsequent transport to the subtropical North Atlantic in boreal winter would be larger. Some support for this hypothesis comes from a prediction of tropical Pacific SST climatology using a model in which instability waves are absent (Seager et al. 1988). Model predicted SST in the NECC region is approximately $1{ }^{\circ} \mathrm{C}$ higher than that observed climatologically during the instability wave season in the Pacific Ocean from June through December. While Seager et al. (1988) state that this discrepancy can be removed with a small change in surface heat flux forcing, the discrepancy could also be due to the exclusion of instability waves.

Locally, SST changes due to the convergence of Reynolds heat flux are controlled by $-\left(\left\langle v^{\prime} T^{\prime}\right\rangle\right)_{y}$. This meridional component is consistently positive throughout the wave season as compared to the zonal component, $-\left(\left\langle u^{\prime} T^{\prime}\right\rangle\right)_{x}$, which reverses sign and has negligible influence on SST when averaged over the wave season. The June 1983 averaged values of $\left\langle v^{\prime} T^{\prime}\right\rangle$ between $0.75^{\circ} \mathrm{S}$ and $0.75^{\circ} \mathrm{N}$ yields a rate of SST increase of $5 \times 10^{-7}{ }^{\circ} \mathrm{C} \mathrm{s}^{-1}$ which, by itself, would increase SST by about $2^{\circ} \mathrm{C}$. Instability wave induced convergence of heat, if assumed to extend over the upper $50 \mathrm{~m}$, is equivalent to a surface flux of about 100 $\mathrm{W} \mathrm{m} \mathrm{m}^{-2}$; the same as the climatologically deduced value for the net atmospheric heat influx (Hastenrath and Lamb 1978). This heating follows a $3^{\circ} \mathrm{C}$ SST cooling by upwelling brought about by the springtime intensification of the zonal wind stress (see Fig. 4). Thus, the waves are important in halting and even reversing the cooling trend thereby affecting local SST as well as the zonal gradient in SST along the equator. For this reason, as well as the waves' role in meridional heat flux, interannual variability in wave activity may have important regional as well as global climatic consequences.

\section{Summary}

Temperature and velocity time series from current meter moorings deployed during the SEQUAL/FOCAL Programs were used to examine instability waves and their role in the near-surface circulation of the equatorial Atlantic Ocean. Wave packets, consisting of two to three oscillations, appeared in late May 1983 and 1984 following the springtime intensification of easterly wind stress and the subsequent development of the SEC. The waves, with central periodicity of 25 days, had meridional velocity fluctuations of 50 to 75 $\mathrm{cm} \mathrm{s}^{-1}$, SST fluctuations of $1^{\circ}$ to $2^{\circ} \mathrm{C}$, and at least a fivefold increase over backgrond levels in TPE and Reynolds fluxes of heat and momentum. These energies and fluxes were maximum on the equator at 10 $m$ depth where values during the wave season were: 1500 to $2000 \mathrm{erg} \mathrm{cm}^{-3}$ for TPE, 1200 to $1500 \mathrm{erg} \mathrm{cm}^{-3}$ for $\rho_{0}\left\langle u^{\prime} v^{\prime}\right\rangle$ and $-15^{\circ}$ to $-30^{\circ} \mathrm{C} \mathrm{cm} \mathrm{s}^{-1}$ for $\left\langle v^{\prime} T^{\prime}\right\rangle$. The waves were anisotropic and spatially inhomogeneous, confined primarily to the mixed layer in the region south of $6^{\circ} \mathrm{N}$ and west of $4^{\circ} \mathrm{W}$. Zonal wavenumber analyses, computed independently for 1983 and 1984, yielded nearly identical results with wavelengths between 1100 and $1200 \mathrm{~km}$ and phase speeds between -50 and $-55 \mathrm{~cm} \mathrm{~s}^{-1}$. In both years the direction of phase propagation was westward while the energy flux was eastward. This eastward energy flux appeared to be due to an eastward progression of the instability itself as opposed to an eastward group velocity.

The 1983 data permitted an estimation of the terms in the perturbation energy budget at $10 \mathrm{~m}$ depth on the equator at $28^{\circ} \mathrm{W}$. TPE, which was predominantly kinetic, increased rapidly in late May with an $e$-folding time of about two weeks. By mid-June TPE began to decrease slowly returning to background levels by the end of July. The explosive increase in TPE was due to barotropic instability with production (primarily by $-\rho_{0}\left\langle u^{\prime} v^{\prime}\right\rangle U_{y}$ ) occurring in the cyclonic shear region of the SEC between the equator and $0.75^{\circ} \mathrm{N}$. The subsequent decrease in TPE was due primarily to the meridional divergence of pressure-work. TPE production by baroclinic instability was negligible because the meridional and zonal components were both small and cancelling. Energy losses by the vertical divergence of pressure-work and turbulent advection of TPE were also small. Like the waves themselves, all of the important terms entering into the perturbation energy balance were seasonally modulated.

Dynamically, the waves decelerated the SEC north of the equator and reduced its cyclonic shear. This occurred coincident with the basinwide overshoot of the ZPG which also decelerates the SEC tending to remove the source of instability. The seasonal modulation of the waves is therefore a result of both barotropic instability and the basinwide adjustment of the pressure field to the seasonal intensification of easterly wind stress. The difference in basin size between the Atlantic and Pacific Oceans would therefore account for the difference in wave season duration of these two oceans by virtue of the difference in pressure field adjustment times. 
The waves also seem to be important in both local and basin-scale heat balances. The southward heat transport due to the waves, while small relative to the total northward cross-equatorial heat transport, was of the same magnitude as the increase in northward heat transport across the equator. Moreover, the wave season coincides with the period of rapid heat gain in the NECC. In effect, the wave-induced perturbation heat fluxes thermostatically regulate the heat storage in the NECC. The meridional convergence of Reynolds heat flux upon the equator increases SST there halting (or even reversing) the seasonal upwelling induced cooling initiated by the springtime intensification of the easterly wind stress. In June 1983 this heat flux convergence on the equator at $28^{\circ} \mathrm{W}$ was $100 \mathrm{~W} \mathrm{~m}^{-2}$, approximately the same as the climatological atmospheric heat influx to the ocean at this time. The effects of the instability waves upon SST, the zonal gradient in SST, and the meridional heat flux suggests that interannual variability in wave activity may have important regional as well as global climatic consequences.

Finally, several features of the instability waves of the equatorial Atlantic Ocean's SEC are unique when compared to observations from other midocean currents. These features are that 1 ) the waves result primarily from barotropic (as opposed to baroclinic) instability, 2) they are amongst the most energetic observed (on a par with western boundary current instabilities), and, perhaps most distinctly, 3) their generation shows a pronounced seasonal modulation. This latter feature is a consequence of the seasonally abrupt easterly wind stress intensification and the rapid adjustment time of the basin. Although of brief duration, the non-linear processes associated with these waves play important dynamic and thermodynamic roles in the seasonal evolution of the equatorial Atlantic's circulation.

Acknowledgments. Support for this work was provided by the Oceanography Section of the National Science Foundation under Grant OCE-8211848 for the collection of the data and Grant OCE-8740380 for their analyses. C. Colin and P. L. Richardson provided the current meter data collected at $0^{\circ} \mathrm{N}, 4^{\circ} \mathrm{W}$ and at $6^{\circ} \mathrm{N}$, $28^{\circ} \mathrm{W}$, respectively. The authors thank T. Y. Tang for many helpful discussions and J. Donovan who assisted with the data processing.

\section{REFERENCES}

Andrews, D. G., and M. E. McIntyre, 1976: Planetary waves in horizontal and vertical shears: The generalized Eliassen-Palm relation and the mean zonal acceleration. J. Atmos. Sci., 33, 20312048.

Brooks, I. H., and P. P. Niiler, 1977: Energetics of the Florida Current. J. Mar. Res., 35, 163-191.

Bryden, H. L., 1979: Poleward heat flux and conversion of available potential energy in Drake Passage. J. Mar. Res., 37, 1-22.

- 1982: Sources of eddy energy in the Gulf Stream recirculation region. J. Mar. Res., 40, 1047-1068.
- E. C. Brady and D. L. Halpern, 1987: Lateral mixing in the equatorial Pacific Ocean. Further Progress in Equatorial Oceanography, E. J. Katz and J. M. Witte, Eds., Nova University Press, 121-132.

Cane, M., and E. S. Sarachik, 1977: Forced baroclinic ocean motions, II: The linear equatorial bounded case. J. Mar. Res., 35, 395432.

Charney, J., and P. G. Drazin, 1961: Propagation of planetary-scale disturbances from the lower into the upper atmosphere. J. Geophys. Res., 66, 83-109.

Cochrane, J. D., F. S. Kelly and C. D. Oiling, 1979: Subthermocline countercurrents in the western equatorial Atlantic Ocean. $J$. Phys. Oceanogr., 9, 724-738.

Colin, C., and S. L. Garzoli, 1987: In situ wind measurements and the ocean response in the equatorial Atlantic during the Programme Français Ocean Climat dans L'Atlantique Equatorial and Seasonal Response of the Atlantic Ocean Experiment. $J$. Geophys. Res., 92, 3741-3750.

Cox, M., 1980: Generation and propagation of 30-day waves in a numerical model of the Pacific. J. Phys. Oceanogr., 10, 11681186.

Dantzler, Jr., H. L., 1977: Potential energy maxima in the tropical and subtropical North Atlantic. J. Phys. Oceanogr., 7, 512-519.

Dewar, W. K., and J. M. Bane, Jr., 1985: Subsurface energetics of the Gulf Stream near the Charleston Bump. J. Phys. Oceanogr., 15, 1771-1789.

Dickson, R. R., 1983: Global summaries and intercomparisons: Flow statistics from long term current meter moorings. Eddies in $\mathrm{Ma}$ rine Science, A. R. Robinson, Ed., Springer-Verlag, 278-353.

Duing, W., P. Hisard, E. Katz, J. Knauss, J. Meincke, L. Miller, K. Moroshkin, G. Philander, A. Rybnikov, K. Voigt and R. Weisberg, 1975: Meanders and long waves in the equatorial Atlantic. Nature, 257, 280-284.

Edmon, H. J., Jr., B. J. Hoskins and M. E. McIntyre, 1980: EliassenPalm cross sections for the troposphere. J. Atmos. Sci., 37, 26002616.

Eliassen, A., and E. Palm, 1960: On the transfer of energy in stationary mountain waves. Geofys. Publ., 22, 1-23.

Gill, A. E., J. S. A. Green and A. J. Simmons, 1974: Energy partition in the large-scale ocean circulation and the production of midocean eddies. Deep-Sea Res., 21, 499-528.

Halpern, D., R. A. Knox and D. S. Luther, 1987: Observations of 20-day period meridional current oscillations in the upper ocean along the Pacific equator. J. Phys. Oceanogr., submitted.

Hansen, D. V., and C. A. Paul, 1984: Genesis and effects of long waves in the equatorial Pacific. J. Geophys. Res., 89, $10431-$ 10440.

Harvey, R. R., and W. C. Patzert, 1976: Deep current measurements suggest long waves in the eastern equatorial Pacific. Science, 193, 883-884.

Hastenrath, S., and P. J. Lamb, 1978: Heat Budget Atlas of the Tropical Atlantic and Eastern Pacific Oceans. University of Wisconsin Press, 112 pp.

Henin, C., P. Hisard and B. Piton, 1986: Observations hydrologiques dans l'Ocean Atlantique equatorial (juillet 1982-aout 1984). Programme Francias Ocean et Climat Atlantique equatorial (FOCAL). Editions de l'ORSTOM. Institut Francais de Recherche Scientifique pour le Developpement en Cooperation. Collection Travaux et Documents $n^{\circ} 196$. Paris, $191 \mathrm{pp}$.

Hisard, P., and C. Henin, 1987: Response of the equatorial Atlantic Ocean to the 1983-1984 wind from the Programme Français Ocean Climat dans L'Atlantique Equatorial cruise data set. $J$. Geophys. Res., 92, 3759-3768.

Holton, J. R., 1974: Forcing of mean flows by stationary waves. $J$. Atmos. Sci., 31, 942-945.

Houghton, R. W., and C. Colin, 1987: Wind-driven meridional eddy heat flux in the Gulf of Guinea. J. Geophys. Res., 92, 1077710786.

Hurlburt, H. H., J. C. Kindle and J. J. O'Brien, 1976; A numerical simulation of the onset of El Niño. J. Phys. Oceanogr., 6, 621631 . 
Katz, E. J., 1981: Dynamic topography of the sea surface in the equatorial Atlantic. J. Mar. Res., 39, 53-63.

Keffer, T., 1983: The baroclinic instability of the Atlantic North Equatorial Current. J. Phys. Oceanogr., 13, 624-631.

Leaman, K. D., R. L. Molinari and P. S. Vertes, 1987: Structure and variability of the Florida Current at $27^{\circ} \mathrm{N}$ : April 1982-July 1984. J. Phys. Oceanogr., 17, 565-583.

Legeckis, R., and G. Reverdin, 1987: Long waves in the equatorial Atlantic Ocean during 1983. J. Geophys. Res., 92, 2835-2842.

$\longrightarrow$, W. Pichel and G. Nesterczuk, 1983: Equatorial long waves in geostationary satellite observations and in a multichannel sea surface temperature analysis. Bull. Amer. Meteor. Soc., 64, 133139.

McPhaden, M. J., J. A. Proehl and L. M. Rothstein, 1986: The interaction of equatorial Kelvin waves with realistically sheared currents. J. Phys. Oceanogr., 16, 1499-1515.

Merle, J., and S. Arnault, 1985: Seasonal variability of the surface dynamic topography in the tropical Atlantic Ocean. J. Mar. Res., 43, 267-288.

Pedlosky, J., 1977: On the radiation of meso-scale energy in the midocean. Deep-Sea Res., 24, 591-600.

—, 1987: Geophysical Fluid Dynamics, 2nd ed. Springer-Verlag, $710 \mathrm{pp}$.

Philander, S. G. H., 1976: Instabilities of zonal currents, 1. J. Geophys. Res., 81, 3725-3735.

- 1978: Instabilities of zonal currents, 2. J. Geophys. Res., 83, 3679-3682.

- and R. C. Pacanowski, 1980: The generation of equatorial currents. J. Geophys. Res., 85, 1123-1136.

- and - 1986: The mass and heat budget in a model of the tropical Atlantic Ocean. J. Geophys. Res., 91, 14 212-14 220.

- W. J. Hurlin and R. C. Pacanowski, 1986: Properties of long equatorial waves in models of the seasonal cycle in the tropical Atlantic and Pacific Oceans. J. Geophys. Res., 91, 14207 14211.

Richardson, P. L., and T. K. McKee, 1984: Average seasonal vari- ations of the Atlantic equatorial currents from historical ship drifts. J. Phys. Oceanogr., 14, 1226-1238.

Rossby, T., 1987: On the energetics of the Gulf Stream at $73^{\circ} \mathrm{W} . J$. Mar. Res., 45, 59-82.

Seager, R., S. E. Zebiak and M. A. Cane, 1988: A model of the tropical Pacific sea surface temperature climatology. J. Geophys. Res., 93, 1265-1280.

Szabo, D., and G. L. Weatherly, 1978: Energetics of the Kuroshio south of Japan. J. Mar. Res., 37, 531-556.

Talley, L. D., 1983: Radiating barotropic instability. J. Phys. Oceanogr., 13, 972-987.

Tennekes, H., and J. L. Lumley, 1972: A First Course in Turbulence. MIT Press, 300 pp.

Weisberg, R. H., 1984: Instability waves observed on the equator in the Atlantic Ocean during 1983. Geophys. Res. Lett., 11, 753756.

- 1987 : Observations pertinent to instability waves in the equatorial oceans. Further Progress in Equatorial Oceanography. E. J. Katz and J. M. Witte, Eds., Nova University Press, 335350.

—_, and A. M. Horigan, 1981: Low-frequency variability in the equatorial Atlantic. J. Phys. Oceanogr., 11, 913-920.

the zonal pressure gradient in the equatorial Atlantic Ocean. $J$. Geophys. Res., 91, $11717-11725$.

- and T. Y. Tang, 1987: Further studies on the response of the equatorial thermocline in the Atlantic Ocean to the seasonally varying Trade Winds. J. Geophys. Res., 92, 3709-3727.

—, A. M. Horigan and C. Colin, 1979: Equatorially trapped Rossby-gravity wave propagation in the Gulf of Guinea. $J$. Mar. Res., 37, 67-87.

- J. H. Hickman, T. Y. Tang and T. J. Weingartner, 1987: Velocity and temperature observations during the seasonal response of the Equatorial Atlantic Experiment at $0^{\circ}, 28^{\circ} \mathrm{W}$. J. Geophys. Res., 92, 5061-5075. 